\title{
The Environment of Warm-Season Elevated Thunderstorms Associated with Heavy Rainfall over the Central United States
}

\author{
JAMES T. MOORE \\ Department of Earth and Atmospheric Sciences, Saint Louis University, St. Louis, Missouri \\ Fred H. GLASS \\ NOAA/National Weather Service Forecast Office, St. Charles, Missouri \\ Charles E. Graves \\ Department of Earth and Atmospheric Sciences, Saint Louis University, St. Louis, Missouri \\ ScotT M. RochetTe \\ State University of New York College at Brockport, Brockport, New York \\ MARC J. SINGER \\ Department of Earth and Atmospheric Sciences, Saint Louis University, St. Louis, Missouri
}

(Manuscript received 9 April 2002, in final form 4 March 2003)

\begin{abstract}
Twenty-one warm-season heavy-rainfall events in the central United States produced by mesoscale convective systems (MCSs) that developed above and north of a surface boundary are examined to define the environmental conditions and physical processes associated with these phenomena. Storm-relative composites of numerous kinematic and thermodynamic fields are computed by centering on the heavy-rain-producing region of the parent elevated MCS. Results reveal that the heavy-rain region of elevated MCSs is located on average about $160 \mathrm{~km}$ north of a quasi-stationary frontal zone, in a region of low-level moisture convergence that is elongated westward on the cool side of the boundary. The MCS is located within the left-exit region of a south-southwesterly lowlevel jet (LLJ) and the right-entrance region of an upper-level jet positioned well north of the MCS site. The LLJ is directed toward a divergence maximum at $250 \mathrm{hPa}$ that is coincident with the MCS site. Near-surface winds are light and from the southeast within a boundary layer that is statically stable and cool. Winds veer considerably with height (about $140^{\circ}$ ) from 850 to $250 \mathrm{hPa}$, a layer associated with warm-air advection. The MCS is located in a maximum of positive equivalent potential temperature $\theta_{e}$ advection, moisture convergence, and positive thermal advection at $850 \mathrm{hPa}$. Composite fields at $500 \mathrm{hPa}$ show that the MCS forms in a region of weak anticyclonic curvature in the height field with marginal positive vorticity advection. Even though surfacebased stability fields indicate stable low-level air, there is a layer of convectively unstable air with maximum$\theta_{e}$ CAPE values of more than $1000 \mathrm{~J} \mathrm{~kg}^{-1}$ in the vicinity of the MCS site and higher values upstream. Maximum$\theta_{e}$ convective inhibition (CIN) values over the MCS centroid site are small (less than $40 \mathrm{~J} \mathrm{~kg}^{-1}$ ) while to the south convection is limited by large values of CIN (greater than $60 \mathrm{~J} \mathrm{~kg}^{-1}$ ). Surface-to-500-hPa composite average relative humidity values are about $70 \%$, and composite precipitable water values average about 3.18 $\mathrm{cm}$ (1.25 in.). The representativeness of the composite analysis is also examined. Last, a schematic conceptual model based upon the composite fields is presented that depicts the typical environment favorable for the development of elevated thunderstorms that lead to heavy rainfall.
\end{abstract}

\section{Introduction}

Mesoscale convective systems (MCSs) account for approximately $30 \%-70 \%$ of the warm-season (April-

Corresponding author address: James T. Moore, Dept. of Earth and Atmospheric Sciences, Saint Louis University, 3507 Laclede Ave., St. Louis, MO 63103.

E-mail: moore@eas.slu.edu
September) precipitation over much of the region between the Rocky Mountains and the Mississippi River (Fritsch et al. 1986). Although much of this rain can be beneficial for agricultural needs and reservoirs, in many cases heavy rainfall associated with convective storms produces a serious threat to life and property. Flash flooding often results from intense, long-duration rainfall associated with MCSs. During the summer of 1993, 
the continuous development and movement of MCSs over portions of the Missouri and upper Mississippi River basins for several months contributed to numerous individual flash-flood events and prolonged large-scale river flooding, resulting in 48 fatalities and economic losses estimated at $\$ 20$ billion (NOAA 1994). Junker et al. (1995) report that during the period from June to September 1993 at least 43 different MCSs produced 24-h rainfall amounts greater than $12.7 \mathrm{~cm}$ (5 in.) throughout the Midwest, contributing to the devastating flooding.

Colman (1990a,b) defined elevated thunderstorms as those that are isolated from surface diabatic effects and occur above frontal surfaces. Colman (1990a) reported a bimodal distribution of elevated thunderstorm activity with a primary maximum in April and a secondary maximum in September for the period of study: September of 1978 through August of 1982. In fact, he recorded over 725 reports of elevated thunderstorms for AprilSeptember for this 4-yr period. Thus, many warm-season MCSs are composed of elevated thunderstorms, which can produce heavy rainfall and even large hail (Grant 1995). Junker et al. (1995) also note that the majority of the summer-1993 heavy-rainfall events had many similarities to elevated thunderstorms, as described by Colman (1990a,b). Predicting both the location and initiation time of elevated thunderstorms can be problematic owing to uncertainty in understanding those mechanisms that release elevated instability. Jankov and Gallus (2002) note that cases in which convection formed north of an east-west boundary were poorly simulated by the Eta numerical model. Furthermore, the current convective parameterization schemes in numerical weather prediction models focus on the initiation of convection through processes associated with the near-surface environment and not processes that take place above a frontal zone (Anderson et al. 2002).

Building upon the work of others (e.g., Maddox et al. 1979; Cotton et al. 1989; Colman 1990a,b; Glass et al. 1995; Junker et al. 1999), the focus of this study is to quantify the synoptic-meso- $\alpha$-scale environment and physical processes favorable for the production of organized elevated thunderstorms (i.e., MCSs) that produce copious rainfall. Recognizing the key processes that initiate and sustain elevated thunderstorms should assist forecasters in anticipating elevated MCS formation and the potential for heavy rainfall.

In this study, 21 warm-season (April-September) heavy-rain events resulting from organized elevated thunderstorms are used to produce composite analyses of basic and derived parameters from rawinsonde data. These composite analyses describe the major features and physical mechanisms contributing to elevated MCSs that produce heavy rainfall. Section 2 discusses the previous work on elevated thunderstorms, and section 3 describes the method adopted in choosing and compositing the cases for this study. In section 4 , the results of the compositing analysis are illustrated by showing key parameters (e.g., low-level moisture convergence, lifted index) that document the environment supportive of elevated thunderstorms. A discussion is also included that examines the representativeness and generality of the composite results. Section 5 summarizes the results and discusses the important physical mechanisms and processes that contribute to the development of elevated thunderstorms accompanied by heavy rain.

\section{Previous research}

As noted earlier, Colman (1990a,b) produced two of the most comprehensive papers to define, document, and illustrate elevated thunderstorms in the United States. He defined them as "a subset of thunderstorms, namely, those occurring above frontal surfaces. Such storms are often isolated from surface diabatic effects, which are often considered fundamental to the development of thunderstorms." Colman (1990a) applied the following criteria to synoptic observations containing thunderstorms to determine if the thunderstorm was likely to have originated from an elevated source: 1) The observation must lie on the cold side of an analyzed front that shows a clear contrast in temperature, dewpoint, and wind. 2) The station's wind, temperature, and dewpoint temperature must be qualitatively similar to the immediately surrounding values. 3) The surface air on the warm side of the analyzed front must have a higher equivalent potential temperature $\theta_{e}$ than the air on the cold side of the front.

As a result of his work, Colman (1990a) identified the following thermodynamic and kinematic characteristics of the elevated thunderstorm environment: 1) strong warm-air advection at $850 \mathrm{hPa}$; 2) strong lowlevel veering of winds with height, from easterly near the surface, to south-southwesterly at $850 \mathrm{hPa}$, to southwesterly at $500 \mathrm{hPa} ; 3$ ) extremely stable surface air with surface lifted indices (LI) greater than $7^{\circ} \mathrm{C} ; 4$ ) a shallow front exhibiting a strong frontal inversion of greater than $5^{\circ} \mathrm{C}$; and 5) a sharply defined front associated with a strong horizontal thermal contrast. He concluded that elevated thunderstorms that occur in these environments are likely the product of frontogenetical forcing in the presence of weak symmetric stability (Colman 1990b).

More recent studies (Augustine and Caracena 1994; Glass et al. 1995) have attempted to isolate common features associated with elevated thunderstorms through a compositing approach. In these studies, either diagnostic or numerical model gridded datasets of individual case studies, centered on the initiation or active convection site, were averaged to obtain composite grids of basic and derived parameters (e.g., temperature advection, absolute vorticity) to examine the synoptic features attending elevated convection. The results from these studies, which are not geographically specific, owing to the compositing procedures, indicated that elevated MCSs most often occur near the maximum in $\theta_{e}$ advection at $850 \mathrm{hPa}$, on the southwest edge of the 
TABLE 1. List of heavy-rainfall events, including starting/ending time/date, maximum rainfall and its location, and number of analyses available for composite.

\begin{tabular}{|c|c|c|c|c|c|}
\hline Event no. & $\begin{array}{l}\text { Starting } \\
\text { time/date }\end{array}$ & $\begin{array}{l}\text { Ending } \\
\text { time/date }\end{array}$ & $\begin{array}{l}\text { Max rainfall } \\
\text { (in.) }\end{array}$ & $\begin{array}{l}\text { Location of } \\
\text { max rainfall }\end{array}$ & $\begin{array}{c}\text { No. of } \\
\text { synoptic } \\
\text { data times } \\
\text { analyzed }\end{array}$ \\
\hline 1 & 1200 UTC 6 Jun 1993 & 2200 UTC 6 Jun 1993 & 6.0 & Central MO & 1 \\
\hline 2 & 0000 UTC 17 Jun 1993 & 1200 UTC 17 Jun 1993 & 6.4 & Southwest MN & 2 \\
\hline 3 & 0000 UTC 13 Jul 1993 & 1300 UTC $13 \mathrm{Jul} 1993$ & 7.0 & Southeast SD & 2 \\
\hline 4 & 2000 UTC 21 Sep 1993 & 1500 UTC 22 Sep 1993 & 8.5 & Northwest MO & 2 \\
\hline 5 & 0500 UTC 24 Sep 1993 & 1900 UTC 24 Sep 1993 & 5.5 & Southwest MO & 1 \\
\hline 6 & 0300 UTC 25 Sep 1993 & 1100 UTC 25 Sep 1993 & 11.0 & Southwest MO & 2 \\
\hline 7 & 2100 UTC 10 Apr 1994 & 1700 UTC 11 Apr 1994 & 10.7 & Southwest MO & 2 \\
\hline 8 & 2100 UTC 27 Apr 1994 & 1700 UTC 28 Apr 1994 & 10.0 & Southeast KS & 2 \\
\hline 9 & 0300 UTC 29 Apr 1995 & 2000 UTC 29 Apr 1995 & 5.7 & South-central KS & 2 \\
\hline 10 & 0900 UTC 16 May 1995 & 1300 UTC 16 May 1995 & 4.0 & East-central MO & 1 \\
\hline 11 & 1200 UTC 17 May 1995 & 0400 UTC 18 May 1995 & 5.9 & Central MO & 2 \\
\hline 12 & 0300 UTC 28 Apr 1996 & 0800 UTC 29 Apr 1996 & 8.8 & South-central IL & 3 \\
\hline 13 & 0100 UTC 7 May 1996 & 0800 UTC 7 May 1996 & 6.1 & North-central MO & 1 \\
\hline 14 & 0300 UTC 8 May 1996 & 1700 UTC 8 May 1996 & 5.4 & North-central MO & 2 \\
\hline 15 & 1700 UTC 14 May 1996 & 0500 UTC 15 May 1996 & 6.0 & East-central MO & 1 \\
\hline 16 & 2200 UTC 16 Jul 1996 & 1500 UTC 17 Jul 1996 & 11.9 & Western IA & 2 \\
\hline 17 & 2200 UTC 17 Jul 1996 & 1400 UTC 18 Jul 1996 & 16.9 & Northeast IL & 2 \\
\hline 18 & 2200 UTC 20 Jul 1996 & 1100 UTC 21 Jul 1996 & 7.9 & West-central MO & 2 \\
\hline 19 & 0600 UTC 19 Aug 1997 & 1300 UTC 19 Aug 1997 & 5.4 & Southwest MO & 1 \\
\hline 20 & 0700 UTC 26 Jul 1998 & 1500 UTC 26 Jul 1998 & 7.9 & South-central MO & 1 \\
\hline 21 & 0700 UTC 27 Jul 1998 & 1300 UTC 27 Jul 1998 & 5.5 & South-central MO & 1 \\
\hline
\end{tabular}

maximum in upper-level (200-300 hPa) divergence, and on the cool side of a west-east-oriented quasi-stationary surface boundary. Both studies emphasized the importance of the southerly low-level jet (LLJ) in organizing and sustaining the elevated convection. Glass et al. (1995) noted that the strongest cases of elevated MCSs with heavy rainfall had an LLJ that was coupled with the 850-hPa $\theta_{e}$ advection maximum, and Augustine and Caracena (1994) stressed the role of the LLJ in terms of its interaction with the frontogenetical circulation near the frontal zone. Other key features of the elevated MCS environment include strong veering of low-level winds, and high $K$ indices and precipitable water (PW) values (typically greater than $150 \%$ of normal) to the south in the warmer air.

More recent case studies by Rochette and Moore (1996) and Moore et al. (1998) have corroborated the above findings and found that the composite fields provide useful signatures for both diagnosing and forecasting elevated thunderstorms with observed and numerical model datasets. As a consequence, the goal of the current study is to expand and quantify the relationships among the various kinematic and thermodynamic fields to depict the major processes fundamental to organized elevated convection.

\section{Datasets and method}

To be considered for this study, organized elevated thunderstorms must have produced at least $10 \mathrm{~cm}$ (4 in.) of rain in $24 \mathrm{~h}$ and either have been initiated or been on going within $\pm 4 \mathrm{~h}$ of either 0000 or 1200 UTC. A search was performed that utilized a local heavy- rainfall-event database from 1993 to 1998 and the National Environmental Satellite, Data, and Information Service Heavy Rainfall Catalog (Borneman and Kadin 1994) for warm-season heavy-rainfall events that met this rainfall criterion and appeared to be associated with elevated thunderstorms. For each potential event, infrared (IR) satellite imagery was used to determine the existence of the parent MCS within $\pm 4 \mathrm{~h}$ of either 0000 or 1200 UTC. Surface plots, surface and elevated stability fields, soundings, and convective stability diagrams were then generated for the prospective cases and compared with radar and/or IR satellite imagery to determine whether the MCS was elevated. Also, the MCS had to meet the three elevated thunderstorm criteria noted by Colman (1990a). If it could not be determined whether a potential case was elevated from the available data, the case was discarded.

A total of 21 heavy-rain events met our criteria and were identified for the study (see Table 1). The starting/ ending time and date listed in Table 1 are the period during which the heavy rainfall occurred. There were cases in which the parent MCS was still in existence after the "ending time"; however, for these cases the IR satellite imagery trends exhibited considerable warming of the cloud tops and a general decrease of deep convection. With only a few exceptions, most of the cases were distinctly nocturnal or had a large nocturnal component. A monthly distribution of the events (Fig. 1) reveals that most of the events occurred during April, May, and July, which is consistent with the climatological description of Colman (1990a).

In this study, the analysis and compositing approach 


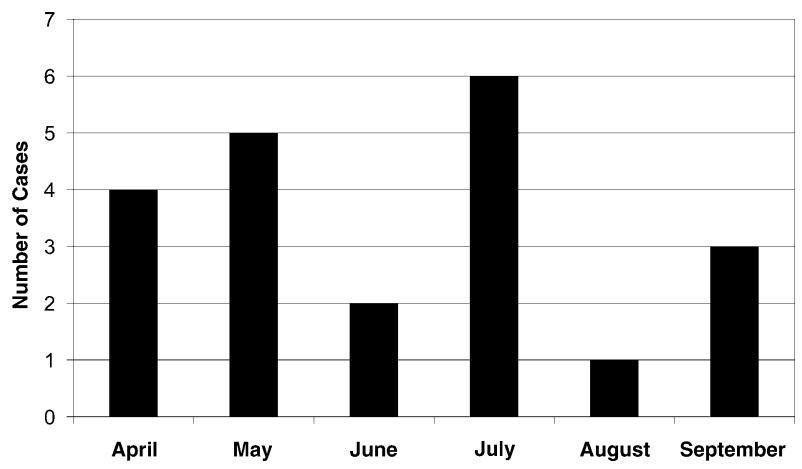

FIG. 1. Monthly distribution of the 21 warm-season (Apr-Sep) heavy-rain events used in the composite analysis.

of Glass et al. (1995) was followed, except observed rawinsonde data were used rather than initial-hour numerical model data. Rawinsonde data from the National Weather Service upper-air network were objectively analyzed on mandatory constant pressure levels using the Barnes (1973) objective analysis scheme on a $31 \times 23$ grid having a $190.5-\mathrm{km}$ grid spacing. Barnes's parameters $c$ and $g$ (the convergence parameter) were set equal to $81900 \mathrm{~km}^{2}$ and 0.2 , respectively. Because the rawinsonde data spacing is approximately $400 \mathrm{~km}$, the chosen values for $c$ and $g$ assure that the objective analysis scheme retains no more than $37 \%$ of the amplitude of the two-delta $(\sim 800 \mathrm{~km})$ waves, following the suggestion of Koch et al. (1983). In addition to basic variables (i.e., temperature $T$, dewpoint temperature $T_{d}$, height, and $u$ and $v$ horizontal wind components), additional derived quantities (e.g., mixing ratio, moisture convergence, absolute vorticity) were computed on the entire grid. An $11 \times 11$ subgrid of basic and derived parameters was subjectively centered nearest either the initiation point of the MCS (the location of the first cells) or the centroid of the most intense convection (as defined below) associated with the active MCS. Centroids were determined at 0000 and/or 1200 UTC by locating the highest reflectivities or meso- $\beta$-scale convective elements (MBEs; see Merritt and Fritsch 1984) in Weather Surveillance Radar-1998 Doppler (WSR88D) data or, when WSR-88D data were not available, from the coldest cloud tops in the IR satellite imagery. For those cases in which several MCSs were present and contributed to heavy rainfall, the analysis was centered on the westernmost MCS at that synoptic hour. The "beginning" of the event is when the first signs of convection erupted; the "ending" of the event is when the radar echoes fell below $40 \mathrm{dBZ}$ and/or when the IR satellite imagery revealed considerable warming of cloud tops. Both 0000 and 1200 UTC data were used for long-lived events in which MCS activity spanned multiple synoptic time periods. Figure 2 displays the positions of the centering points used for the elevated MCS centroid for all 21 cases listed in Table 2, indicating that most of the MCSs occurred in the mid-

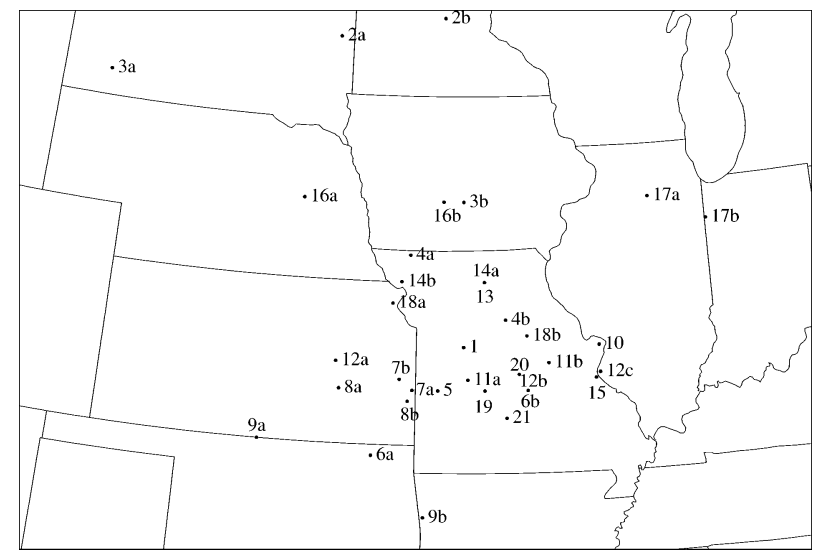

FIG. 2. Locations of the MCS centroids for the 35 individual analysis times used in the composite analysis. Numbers in this diagram correspond to the centroid numbers listed in Table 2.

TABLE 2. Centroid information for heavy-rain cases listed in Table 1. Centroid number corresponds to case number listed in Table 1 and plotted in Fig. 1. Alphabetical suffix is noted for long-lived events that spanned multiple synoptic data times.

\begin{tabular}{|c|c|c|c|}
\hline $\begin{array}{c}\text { Centroid } \\
\text { no. }\end{array}$ & Time/date & $\begin{array}{l}\text { Lat/lon } \\
\left({ }^{\circ} \mathrm{N} /{ }^{\circ} \mathrm{W}\right)\end{array}$ & $\begin{array}{c}\text { Centroid } \\
\text { distance } \\
\text { from } \\
\text { boundary } \\
(\mathrm{km})\end{array}$ \\
\hline 1 & 1200 UTC 6 Jun 1993 & $38.8 / 93.5$ & 425 \\
\hline $2 \mathrm{a}$ & 0000 UTC 17 Jun 1993 & $44.6 / 96.8$ & 200 \\
\hline $2 b$ & 1200 UTC 17 Jun 1993 & $45.0 / 94.0$ & 222 \\
\hline $3 a$ & 0000 UTC 13 Jul 1993 & $43.5 / 102.8$ & 170 \\
\hline $3 b$ & 1200 UTC 13 Jul 1993 & $41.5 / 93.5$ & 234 \\
\hline $4 a$ & 0000 UTC 22 Sep 1993 & $40.5 / 94.8$ & 106 \\
\hline $4 b$ & 1200 UTC 22 Sep 1993 & $39.3 / 92.5$ & 170 \\
\hline 5 & 1200 UTC 24 Sep 1993 & $38.0 / 94.1$ & 255 \\
\hline $6 a$ & 0000 UTC 25 Sep 1993 & $36.8 / 95.6$ & 155 \\
\hline $6 b$ & 1200 UTC 25 Sep 1993 & $38.0 / 92.0$ & 266 \\
\hline $7 \mathrm{a}$ & 0000 UTC 11 Apr 1994 & $38.0 / 94.7$ & 213 \\
\hline $7 b$ & 1200 UTC 11 Apr 1994 & $38.2 / 95.0$ & 213 \\
\hline $8 \mathrm{a}$ & 0000 UTC 28 Apr 1994 & $38.0 / 96.4$ & 340 \\
\hline $8 \mathrm{~b}$ & 1200 UTC 28 Apr 1994 & $37.8 / 94.8$ & 85 \\
\hline $9 a$ & 0000 UTC 29 Apr 1995 & $37.0 / 98.2$ & 50 \\
\hline $9 b$ & 1200 UTC 29 Apr 1995 & $35.7 / 94.4$ & 133 \\
\hline 10 & 1200 UTC 16 May 1995 & $38.8 / 90.3$ & 120 \\
\hline $11 \mathrm{a}$ & 1200 UTC 17 May 1995 & $38.2 / 93.4$ & 128 \\
\hline $11 \mathrm{~b}$ & 0000 UTC 18 May 1995 & $38.5 / 91.5$ & 89 \\
\hline $12 \mathrm{a}$ & 0000 UTC 28 Apr 1996 & $38.5 / 96.5$ & 167 \\
\hline $12 b$ & 1200 UTC 28 Apr 1996 & $38.0 / 92.0$ & 155 \\
\hline $12 \mathrm{c}$ & 0000 UTC 29 Apr 1996 & $38.3 / 90.3$ & 149 \\
\hline 13 & 0000 UTC 7 May 1996 & $40.0 / 93.0$ & 340 \\
\hline $14 \mathrm{a}$ & 0000 UTC 8 May 1996 & $40.0 / 93.0$ & 149 \\
\hline $14 b$ & 1200 UTC 8 May 1996 & $40.0 / 95.0$ & 55 \\
\hline 15 & 0000 UTC 15 May 1996 & $38.2 / 90.4$ & 298 \\
\hline $16 \mathrm{a}$ & 0000 UTC 17 Jul 1996 & $41.5 / 97.5$ & 43 \\
\hline $16 b$ & 1200 UTC 17 Jul 1996 & $41.5 / 94.0$ & 128 \\
\hline $17 \mathrm{a}$ & 0000 UTC 18 Jul 1996 & $41.5 / 88.9$ & 85 \\
\hline $17 b$ & 1200 UTC 18 Jul 1996 & $41.0 / 87.5$ & 43 \\
\hline $18 \mathrm{a}$ & 0000 UTC 21 Jul 1996 & $39.6 / 95.2$ & 64 \\
\hline $18 b$ & 1200 UTC 21 Jul 1996 & $39.0 / 92.0$ & 111 \\
\hline 19 & 1200 UTC 19 Aug 1997 & $38.0 / 93.0$ & 40 \\
\hline 20 & 1200 UTC 26 Jul 1998 & $38.3 / 92.2$ & 128 \\
\hline 21 & 1200 UTC 27 Jul 1998 & $37.5 / 92.5$ & 128 \\
\hline
\end{tabular}


Mississippi River valley, which agrees with Colman's (1990a) climatological description. From the 35 individual analyses, the subgrids were averaged to obtain the composited fields.

The resultant composite analyses are displayed in a grid centered over Missouri; this is for geographic reference and distance scaling only, because each subgrid was centered over a different location and time. The composites are storm relative and are intended to display the spatial orientation and relative magnitudes of the basic and derived parameters with respect to the heavy rainfall region of the elevated MCS, not with respect to a specific geographic location or a particular point in time.

\section{Composite results}

\section{a. Surface and kinematic upper-air fields}

Subjectively analyzed surface maps from the 35 synoptic times included in the 21 events were subjectively composited by the authors to define the average position of the surface boundary. On average, the surface boundary is oriented west-east and about $160 \mathrm{~km}$ south of the MCS centroid (see Fig. 3a). However, as noted in Table 2, the distance between the MCS position and the surface boundary varied from as little as 40 to as much as $425 \mathrm{~km}$, illustrating the large variance of position of the elevated convection with respect to the surface boundary. However, $80 \%$ of the MCSs formed within $240 \mathrm{~km}$ of the surface boundary. The 925-hPa low-level boundary is diagnosed as a west-east baroclinic zone of moderate strength (approximately $2^{\circ} \mathrm{C}$ over $150 \mathrm{~km}$ ) across the south-central portion of the grid (Fig. 3a). At $850 \mathrm{hPa}$ the baroclinic zone is shifted farther north (Fig. $3 b)$. The location of the elevated MCS centroid agrees well with the frontal-type heavy rain setting described by Maddox et al. (1979). This location is consistent with findings by Colman (1990a), but his average elevated thunderstorm position associated with warm and stationary fronts is about $40 \mathrm{~km}$ farther north into the cold air than our MCS average position. This difference can be at least partly explained by the fact that we are using centroids of elevated MCSs inferred from radar and IR satellite imagery, whereas Colman's findings were based on synoptic surface observations. The elevated MCS centroid is located within the low-level $\theta_{e}$ gradient, just to the east of a weak north-south ridge axis, with maximum $\theta_{e}$ values to the south-southwest of the active MCS (Figs. 3c,d). Previous studies (Glass et al. 1995; Junker et al. 1999; Shi and Scofield 1987; Juying and Scofield 1989) show similar relationships between lowlevel $\theta_{e}$ and MCS location.

Given the location of elevated MCSs with respect to low-level baroclinic zones, it is likely that frontogenetical forcing plays a role in their existence. Our current compositing software would not allow for the compositing of frontogenesis; however, Petterssen's two-di- mensional frontogenesis (Petterssen 1956) was computed at both 925 and $850 \mathrm{hPa}$ for each of the 35 analysis times. Frontogenesis values at both levels were interpolated to the position of the centroid and plotted versus time of year (Fig. 4). There were many instances in which the frontogenesis values were greater to the north of the centroid at $850 \mathrm{hPa}$ and to the south of the centroid at $925 \mathrm{hPa}$; thus, our values likely underestimate the frontogenesis values. As seen in Fig. 4, positive frontogenesis values were present in over $80 \%$ (64 out of $70)$ of the calculations. The magnitude was typically greater in the spring when thermal gradients are more pronounced. Frontogenesis implies the presence of a direct thermal circulation that would enhance the upward vertical motion in the vicinity of the frontal zone. Augustine and Caracena (1994) found a similar relationship for large MCSs in the collective group they studied.

The low-level wind, thermal, and moisture fields, resultant advections, and regions of forcing play critical roles in determining where elevated thunderstorms yielding heavy rain may develop and persist. The composite $925-\mathrm{hPa}$ wind and moisture convergence (computed as $-\boldsymbol{\nabla} \cdot q \mathbf{V}$ ) fields (Figs. 5a,c) depict the lower portion of both the frontal zone and the low-level wind maximum. The elevated MCS centroid is located about $600 \mathrm{~km}$ downstream from the $925-\mathrm{hPa}$ wind maximum in a region of weak cyclonic curvature where the winds decrease and back from south to southeast. The favored location of elevated thunderstorms is north of the axis of maximum moisture convergence.

Farther aloft, the $850-\mathrm{hPa}$ composite reveals the heaviest rain associated with the elevated MCS is located in the left-exit region of a weakly anticyclonically curved, southwesterly wind maximum (Fig. 5b). This is consistent with the results of Maddox et al. (1979) for frontal and mesohigh events and also with the heavy rain location identified by Junker et al. (1999). The 850$\mathrm{hPa}$ wind maximum is positioned approximately 400 $\mathrm{km}$ upstream of the MCS centroid. The orientation and magnitude of the $850-\mathrm{hPa}$ LLJ is consistent with Bonner (1968) and others who have documented the role of the LLJ in the convective environment. The composite LLJ is oriented nearly normal to the low-level thermal and moisture fields, resulting in significant advections and forcing above the planetary boundary layer. Moisture convergence at $850 \mathrm{hPa}$ (Fig. 5d) is maximized just south of the MCS centroid.

The composite map of 850 -hPa $\theta_{e}$ advection (Fig. 6c) depicts a large region of positive $\theta_{e}$ advection (greater than $1 \mathrm{~K} \mathrm{~h}^{-1}$ ) that is nearly coincident with the elevated MCS location. This advection of higher- $\theta_{e}$ air is critical in the destabilization process by promoting elevated convective instability above the surface boundary. Glass et al. (1995) and Junker et al. (1999) found similar patterns of $850-\mathrm{hPa} \theta_{e}$ advection; however, their heavy rainfall location was shifted just south of the maximum 850-hPa $\theta_{e}$ advection. 

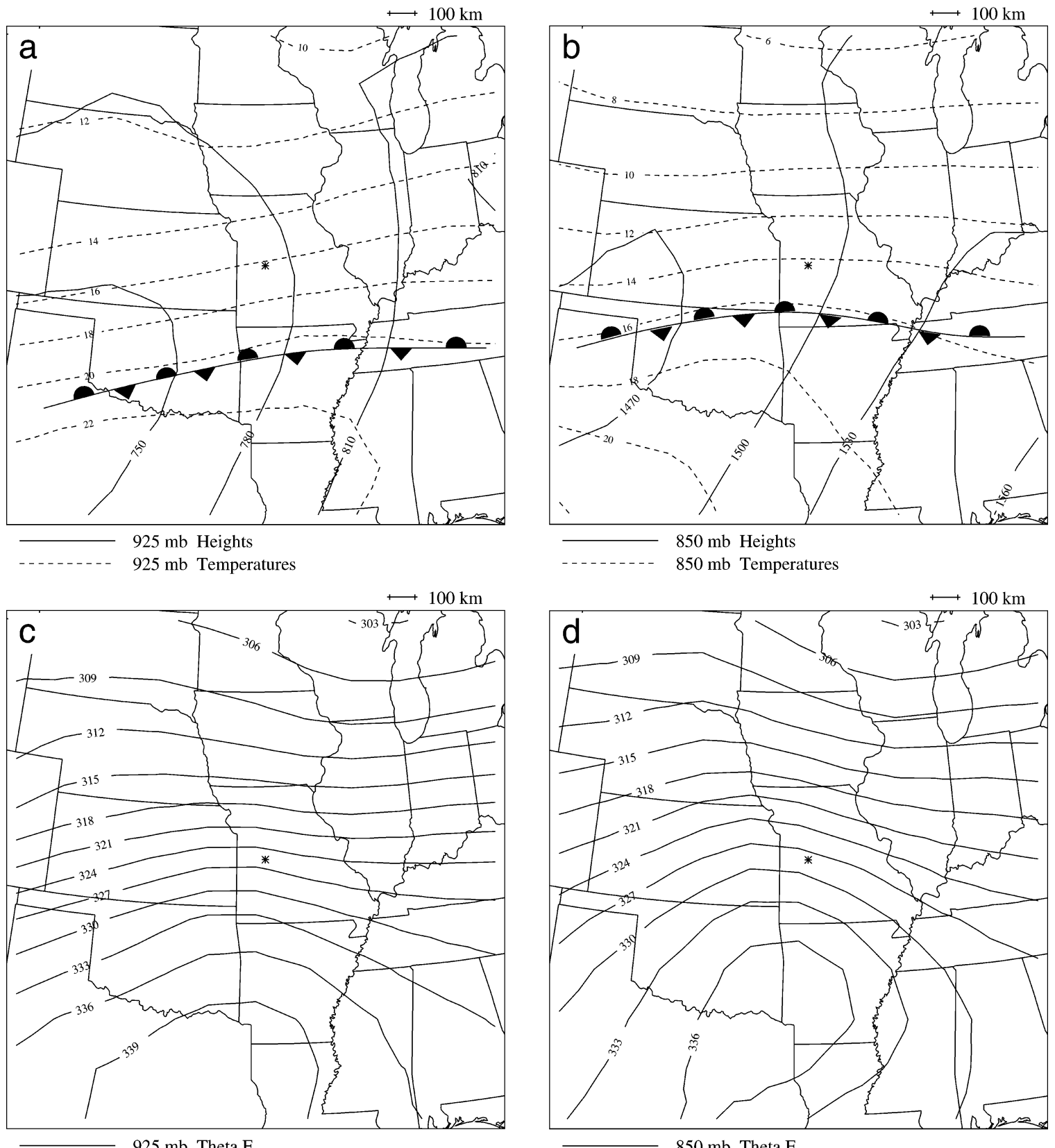

FIG. 3. Composite analysis of (a) 925 -hPa heights (solid, gpm) and temperatures (dashed, ${ }^{\circ} \mathrm{C}$ ) and subjectively analyzed composite surface frontal position (using standard frontal notation); (b) 850-hPa heights (solid, gpm) and temperatures (dashed, ${ }^{\circ} \mathrm{C}$ ) and subjectively analyzed frontal boundary; (c) $925-\mathrm{hPa} \theta_{e}(\mathrm{~K})$; and (d) $850-\mathrm{hPa} \theta_{e}(\mathrm{~K})$. Star indicates the elevated MCS centroid, which is about $160 \mathrm{~km}$ north of the surface boundary. (Note: map background is for scaling purposes only.)

Moisture convergence values at $850 \mathrm{hPa}$ of $0.8 \mathrm{~g}(\mathrm{~kg}$ h) $)^{-1}$ (Fig. 5d) are nearly coincident with the $\theta_{e}$ advection maximum and downstream from the maximum in the moisture transport vectors (Fig. 6b). The 850-hPa moisture convergence maximum is slightly stronger than that at $925 \mathrm{hPa}$ and is more focused in a region about 200 $\mathrm{km}$ south of the MCS centroid, although it does reveal an axis to the west-southwest. The location of the heavy rain with respect to the maximum $850-\mathrm{hPa}$ moisture convergence in our study differs from the results of Junker et al. (1999). They found (see their Fig. 11) the maximum moisture convergence at $850 \mathrm{hPa}$ centered about $2^{\circ}$ latitude north of the heavy rainfall centroid. They postulated that in their cases the initial convection was rooted in the boundary layer near the zone of surface convergence but south of the $850-\mathrm{hPa}$ moisture convergence. The initial convection likely formed west of the observed rainfall maximum and then moved east- 


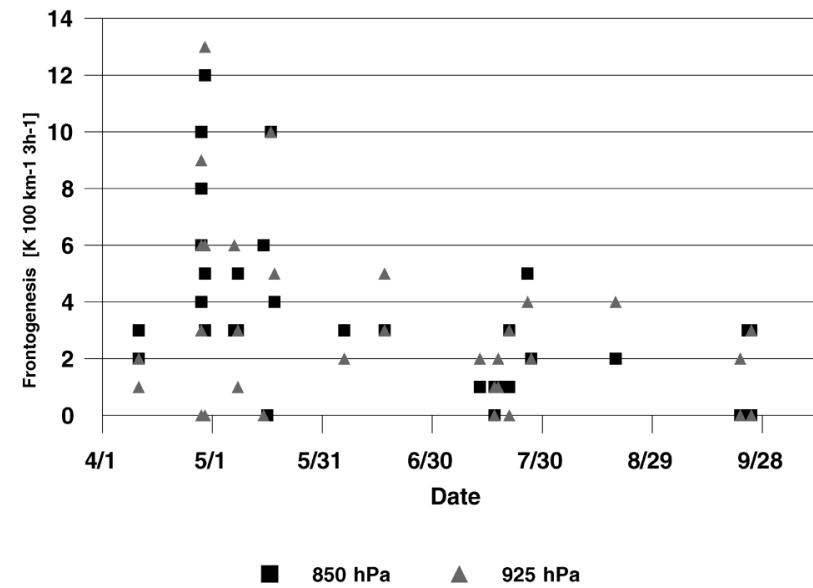

FIG. 4. Scatterplot of Petterssen's 2-D form of frontogenesis computed for all 35 analysis times at 925 and $850 \mathrm{hPa}\left[\mathrm{K}(100 \mathrm{~km})^{-1}(3\right.$ h) ${ }^{-1}$ ] vs date/time of analysis.

ward with the mean flow. In the current study, however, convection formed north of the $850-\mathrm{hPa}$ (and $925 \mathrm{hPa}$ ) moisture convergence maximum. In none of our cases was convection found south of the surface frontal boundary, which could have subsequently moved northward into the cold air. This result further attests to the elevated nature of the convection in this composite study.

Junker et al. (1999) note that a wide LLJ contributes to an elongated region of moisture convergence, thereby increasing the potential for merging and training of cells (i.e., echoes moving over the same geographic location). They also observe that heavy rainfall cases accompanied by training convection typically are associated with an axis of moisture convergence that is parallel to the midlevel flow; our results corroborate their conclusions. When the midlevel flow is approximately parallel to the axis of low-level moisture convergence, convection forms upstream and trains eastward, parallel to the quasi-stationary boundary. Many of the cases we examined could be categorized as "persistent elongated convective systems" (Anderson and Arritt 1998): an MCS that fulfills the size and duration criteria, but not the shape criterion, of the mesoscale convective complex (MCC) definition described by Maddox (1980).

Figure 6d reveals that elevated MCSs tend to be located within a region of positive thermal advection (about $0.4^{\circ} \mathrm{C} \mathrm{h}^{-1}$ ) at $850 \mathrm{hPa}$. This location and this magnitude agree favorably with heavy-rain events studied by Junker et al. (1999) and values found by Maddox (1983) for MCC environments.

The composite fields at $700 \mathrm{hPa}$ showed similar spatial relationships to the MCS locations that were found at $850 \mathrm{hPa}$, although the amplitudes of the patterns were weaker. For example, the $700-\mathrm{hPa}$ winds were about 2 $\mathrm{m} \mathrm{s}^{-1}$ weaker and more westerly (about $20^{\circ}-30^{\circ}$ veer with height) than the $850-\mathrm{hPa}$ winds. This veering with height is consistent with the warm-air advection diagnosed throughout the 850-700-hPa layer (not shown).

The elevated MCS is typically located at the inflection point in the height field in the midlevel southwesterly flow (Fig. 7). A weak short-wave trough, depicted by the thick dashed line, is evident in the 500-hPa height and vorticity fields approximately $1000 \mathrm{~km}$ upstream, with neutral vorticity advection over the elevated MCS region. Further inspection revealed that negative vorticity advection was present over the MCS centroid in less than $30 \%$ of the cases, with the remaining cases having neutral to weak positive vorticity advection. Maddox and Doswell (1982) have commented that many intense convective storms form in regions of neutral to weakly positive vorticity advection. The presence of heavy-rain-producing elevated MCSs in regions of weak positive vorticity advection suggests that low-level warm-air advection/isentropic lift play a significant role in producing meso- $\alpha$-scale vertical motion for these events. Data from $500 \mathrm{hPa}$ reveal continued veering of midtropospheric winds as they are basically west-southwest over the entire domain; a jet axis (not shown) is found west of the MCS location. This synoptic pattern is similar to that noted by Maddox et al. (1979) for the frontal and mesohigh flash-flood scenarios where heavy rainfall is predominantly located west of the midtropospheric ridge axis.

Examination of the upper-level flow revealed that it was weakly anticyclonic and slightly diffluent. At 250 $\mathrm{hPa}$ there is a slightly anticyclonically curved jet streak of moderate strength (greater than $40 \mathrm{~m} \mathrm{~s}^{-1}$ or $80 \mathrm{kt}$; Fig. 8a) well to the northeast of the active MCS site, indicating that the MCS is located in the right-entrance region of the upper-level jet (ULJ) - a region favored for divergence aloft (Moore and VanKnowe 1992). The right-entrance region of the ULJ is characterized by wind vectors that are "cutting" across isotachs toward stronger wind speeds. This observation suggests that air parcels are accelerating poleward, thereby enhancing the divergence production at this level.

The elevated MCS is centered within a divergence maximum of greater than $2.5 \times 10^{-5} \mathrm{~s}^{-1}$ (Fig. 8b) associated with the entrance region of the ULJ. This result varies somewhat from McNulty (1978), who found that severe convection tends to develop in the divergence gradient south of a divergence maximum aloft. Junker et al. (1999) and Glass et al. (1995) also found the location of heaviest rainfall to be in the gradient region south of the maximum values of $250-\mathrm{hPa}$ divergence. It is quite possible that our results vary from these previous studies because the MCSs in our study were often active at the time of the diagnosis. Thus, MCS-induced divergence likely increased divergence values locally. The effect of MCS-induced perturbations on the composite fields will be addressed more completely in section $4 d$. 

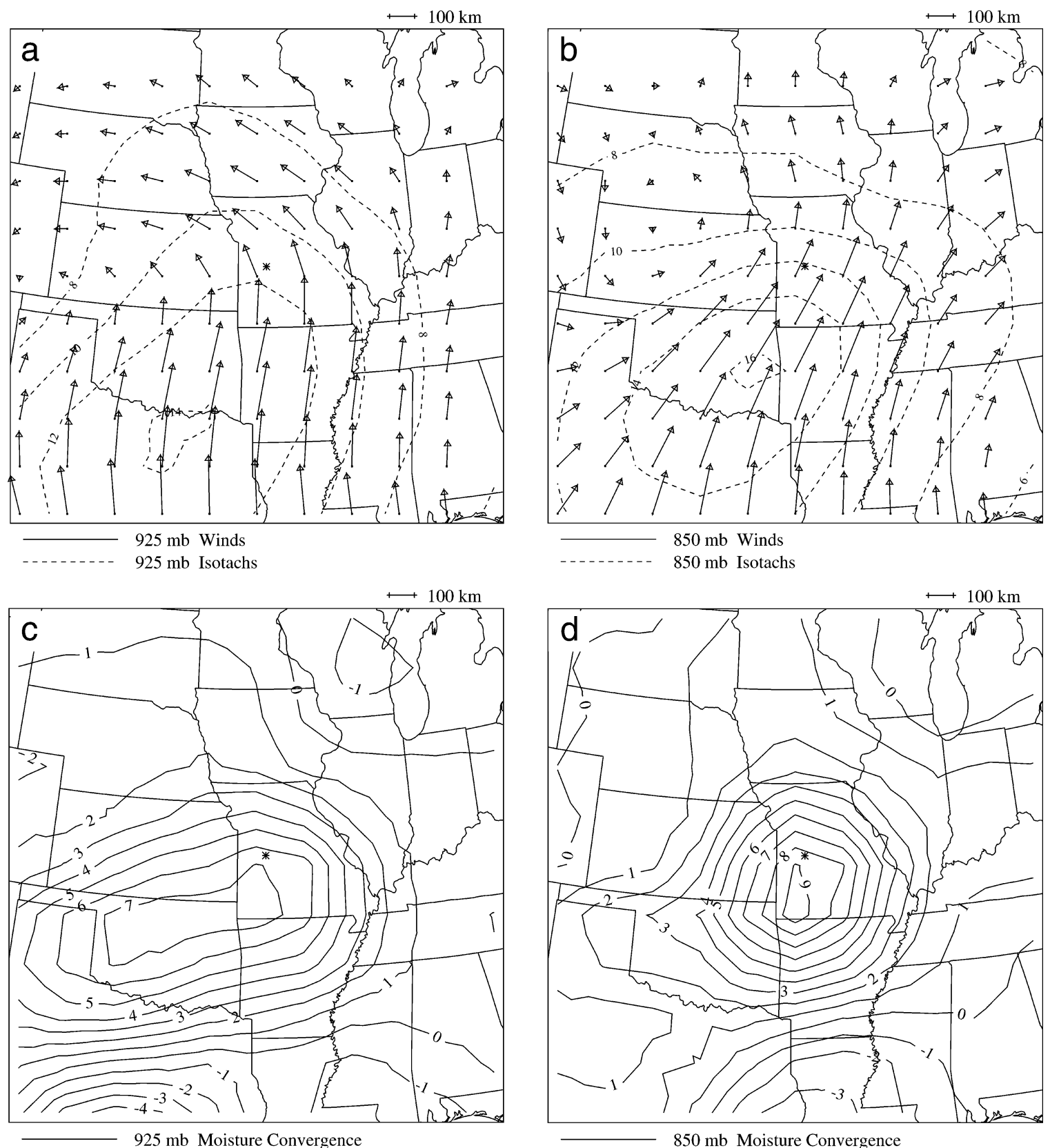

FIG. 5. Composite analysis of (a) 925-hPa wind vectors and isotachs (dashed, $\mathrm{m} \mathrm{s}^{-1}$ ), (b) 850-hPa wind vectors and isotachs (dashed, $\mathrm{m}$ $\left.\mathrm{s}^{-1}\right)$, (c) $925-\mathrm{hPa}$ moisture convergence $\left[10^{-1} \mathrm{~g}(\mathrm{~kg} \mathrm{~h})^{-1}\right]$, and (d) $850-\mathrm{hPa}$ moisture convergence $\left[10^{-1} \mathrm{~g}(\mathrm{~kg} \mathrm{~h})^{-1}\right]$.

\section{b. Stability and moisture fields}

Because elevated thunderstorms, by definition, form above the boundary layer, one would expect surface or low-level-based stability indices to be poor indicators of atmospheric stability. Figure 9a shows the composite plot of the mean parcel LI, computed using a parcel based upon the average potential temperature and mixing ratio of the lowest $100 \mathrm{hPa}$. The horizontal distribution of LI parallels the north-south gradient in the low-level temperature and $\theta_{e}$ fields characteristic of the frontal zone. The mean parcel $\mathrm{LI}$ is around $+4^{\circ} \mathrm{C}$ at the elevated MCS centroid (Fig. 9a), with stability decreasing to the south. The positive LI is expected, given that the MCS lies north of the surface boundary where the low-level air is cooler and more statically stable. The pattern of the Showalter index (SI) field (Fig. 9b) is similar to that of the LI.

CAPE was computed using the same parcel described in the computation of the mean parcel LI. Like the LI and SI, the horizontal distribution of the mean parcel 

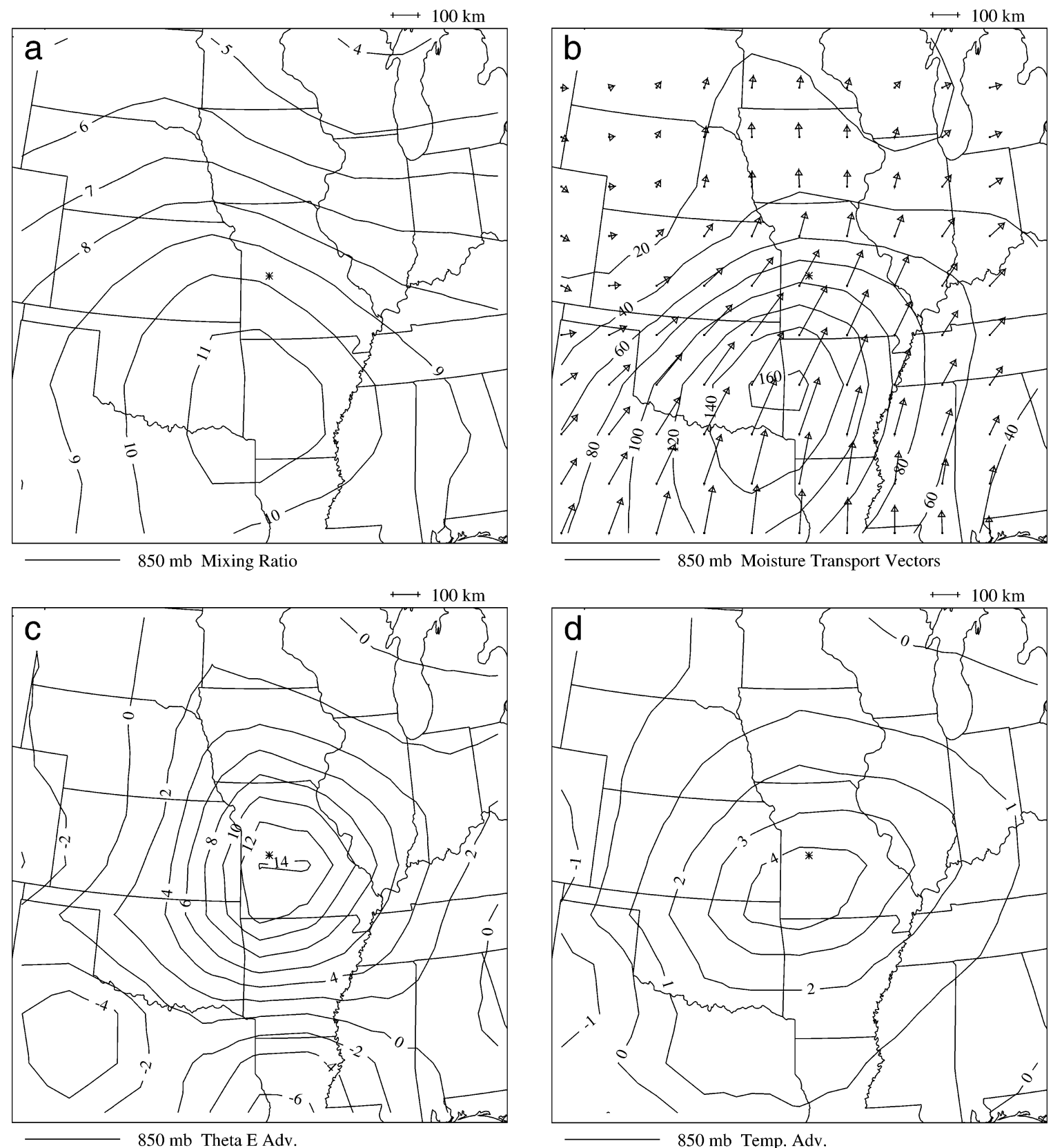

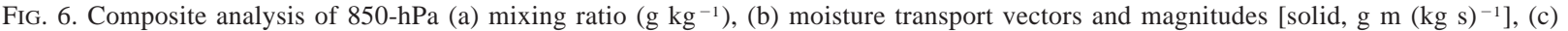
$\theta_{e}$ advection $\left(10^{-1} \mathrm{~K} \mathrm{~h}^{-1}\right)$, and (d) temperature advection $\left(10^{-1} \mathrm{~K} \mathrm{~h}^{-1}\right)$.

CAPE (Fig. 10a) is representative of the boundary layer moisture and temperature stratification, which is dictated by the frontal zone. The elevated MCS centroid is located within the north-south gradient of modest CAPE values (around $600 \mathrm{~J} \mathrm{~kg}^{-1}$ ), with greater values to the south. Even though there is positive mean parcel CAPE in the vicinity of the elevated MCS centroid, large values of convective inhibition (CIN; Fig. 10c), greater than $110 \mathrm{~J} \mathrm{~kg}^{-1}$, suppress surface-based convection. In addition, there is no diagnosed forcing to lift a near-surface parcel to its level of free convection
(LFC). Almost all of the cases investigated displayed little to no convection south of the frontal boundary, consistent with the inability of low-level parcels to overcome the negative buoyancy implied by these large CIN values.

As discussed by Williams and Renno (1993), Doswell and Rasmussen (1994), and, more recently, Rochette et al. (1999), parcel selection is critical when evaluating the potential for convection-particularly elevated convection. Max- $\theta_{e}$ CAPE, which is the CAPE based on lifting the parcel with the highest $\theta_{e}$ in the lowest 300 


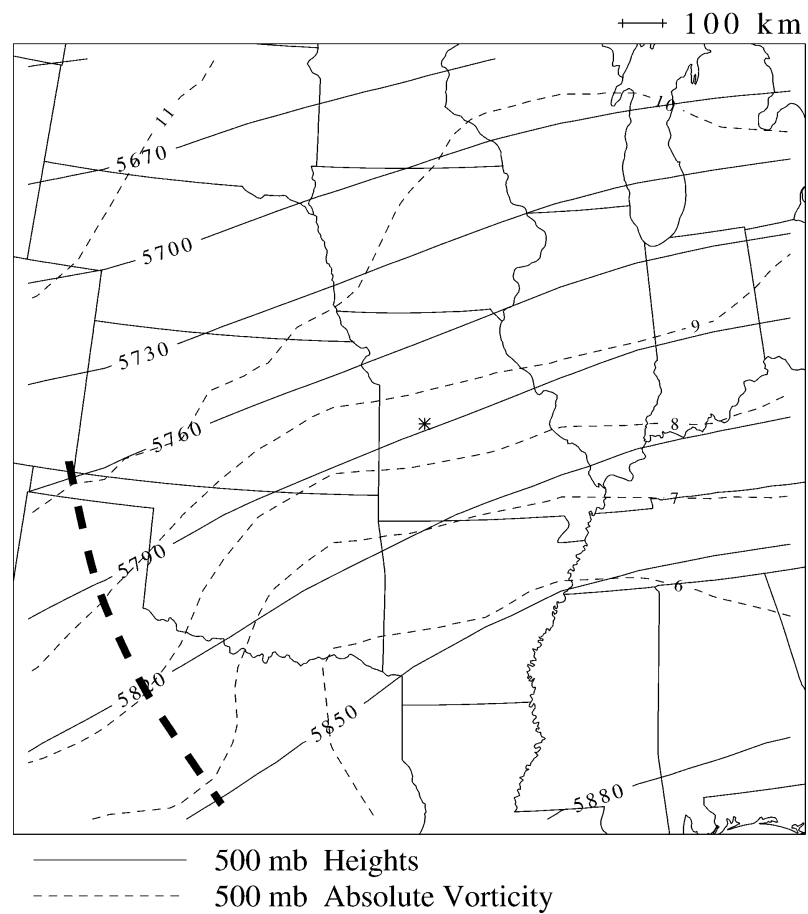

FIG. 7. Composite analysis of 500-hPa heights (solid, gpm) and absolute vorticity (dashed, $10^{-5} \mathrm{~s}^{-1}$ ). Thick dashed line indicates position of the weak short-wave trough.

$\mathrm{hPa}$ of the troposphere, was also composited. Figure $10 \mathrm{~b}$ reveals horizontal distributions similar to the other stability parameters; however, max $-\theta_{e}$ CAPE values are near $1250 \mathrm{~J} \mathrm{~kg}^{-1}$ at the MCS centroid location. This value is more than 2 times the mean parcel CAPE, which illustrates that greater positive buoyancy is realized by lifting a parcel along or above the sloped frontal zone. Similar to the mean parcel CIN, the $\max -\theta_{e}$ CIN is substantial (greater than $50 \mathrm{~J} \mathrm{~kg}^{-1}$ ) south of the MCS centroid. However, the MCS centroid is located within a valley of max- $\theta_{e}$ CIN (Fig. 10d), thus requiring less forced upward vertical motion to overcome negative buoyancy. Thus, it is critical to consider both $\max -\theta_{e}$ CAPE and CIN when evaluating where elevated convection may erupt, given favorable lift and moisture.

A comparison of the above observations of stability fields from our composites with those found by Colman (1990a,b) yields some similarities and some noteworthy differences. Values of LI and SI (LI-85 in Colman) were positive in both studies but varied in magnitude. This variance can at least partly be explained by differences in method: our values were derived from composites, whereas those in the Colman study were the mean of all soundings. The most significant differences found centered around the stability stratification. Colman (1990a) found that elevated thunderstorms typically occur in a stable hydrostatic environment; however, stability varied with the individual cases. He concluded that normally there was an "absence of significant CAPE," and MAPE values (analogous to $\max -\theta_{e}$
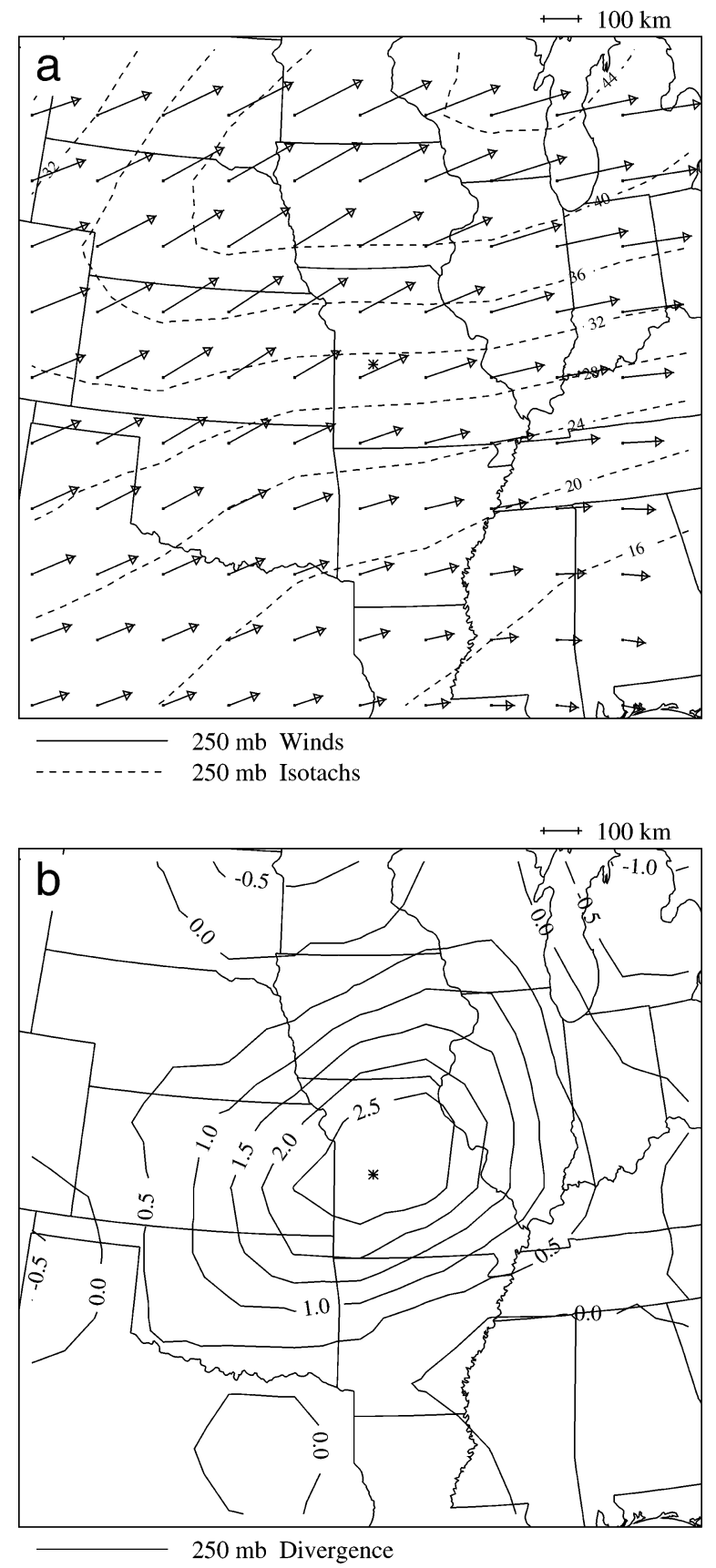

FIG. 8. Composite analysis of 250-hPa (a) wind vectors and isotachs (dashed, $\mathrm{m} \mathrm{s}^{-1}$ ) and (b) divergence $\left(10^{-5} \mathrm{~s}^{-1}\right)$.

CAPE) were generally low. The elevated MCSs in the current study formed in a region of substantial $\max -\theta_{e}$ CAPE (greater than $1000 \mathrm{~J} \mathrm{~kg}^{-1}$ ). Our findings may be a reflection of the fact that we are dealing with organized elevated convective systems, rather than just the presence of an elevated thunderstorm at a station.

Doswell et al. (1996) emphasize the role of the precipitation efficiency (PE) of an MCS in evaluating its rainfall potential. Defined as the ratio of the mass of 

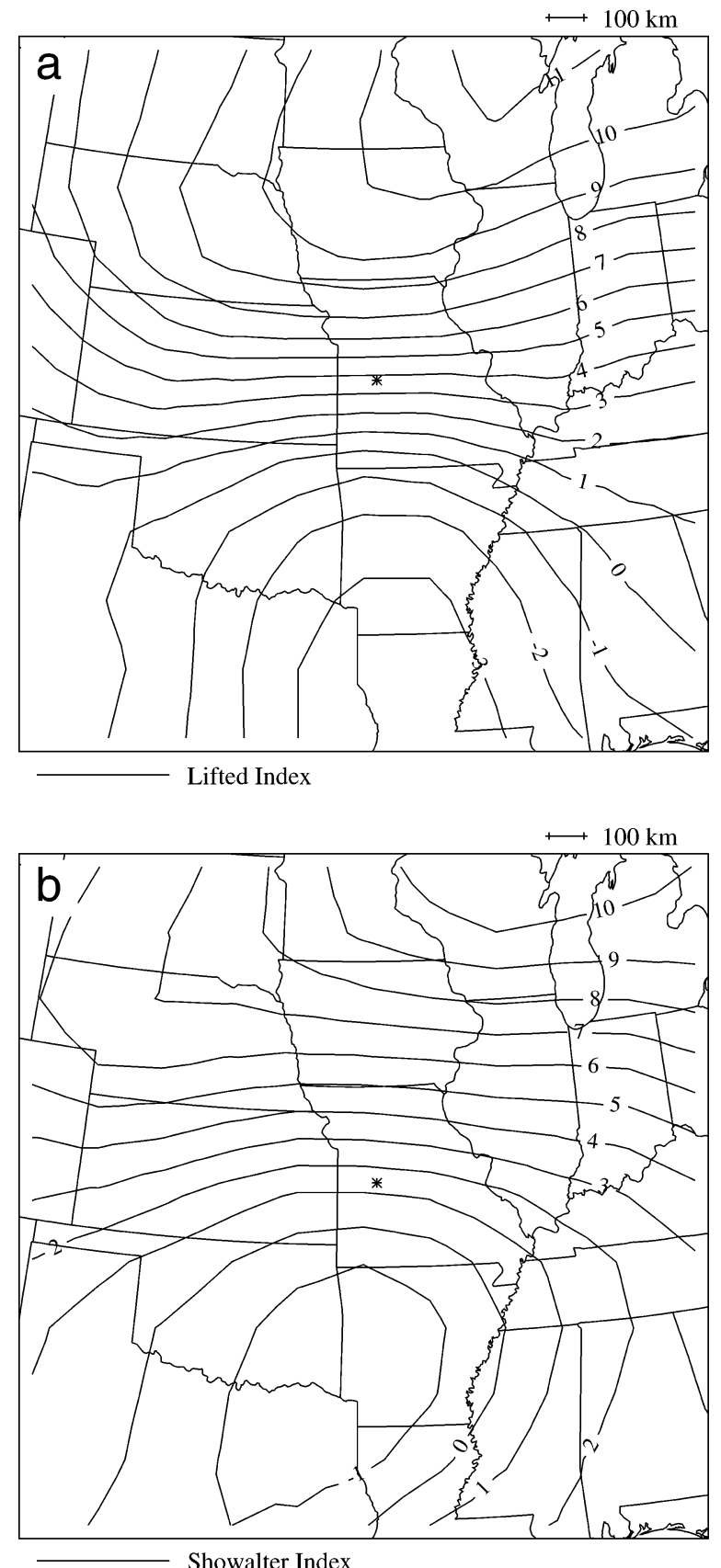

FIG. 9. Composite analysis of (a) LI $\left({ }^{\circ} \mathrm{C}\right)$, computed using the mean parcel from the lowest $100 \mathrm{hPa}$, and (b) SI $\left({ }^{\circ} \mathrm{C}\right)$.

water falling as precipitation to the influx of water vapor mass into the cloud, PE is a difficult parameter to quantify either in the preconvective environment or during an MCS event. However, as Doswell et al. (1996) point out, it is important to anticipate the PE of the MCS in a general sense by asking how likely it is that the potential flood-producing storm is going to have high PE. Some factors believed to affect the PE of an MCS include PW, subcloud-layer relative humidity, droplet size spectrum within the cloud, environmental relative hu- midity, environmental vertical wind shear, warm cloud depth, and entrainment rates within the individual cells. Several of these factors are very difficult to ascertain with operational datasets, especially at the scale of the phenomena. Although a full evaluation of each of these factors is beyond the scope and intent of this study, we wish to evaluate a few of the most widely accepted variables that affect $\mathrm{PE}$ and heavy rainfall potential: $\mathrm{PW}$ and mean environmental relative humidity (MERH; averaged from the surface to $500 \mathrm{hPa}$ ).

The PW value is $1.2-1.3$ in. $(3.1-3.3 \mathrm{~cm})$ at the elevated MCS centroid (Fig. 11a), with the axis of higher values extending to the south concurrent with the moist southerly low-level flow. These values are lower than those found in heavy rainfall studies by Maddox et al. (1979), Glass et al. (1995), and Junker et al. (1999). Among possible reasons for the lower values are 1) that ambient moisture values tend to be lower in the spring and 2) that our study focuses strictly on elevated thunderstorms rather than on a collection of surface-based and elevated convection; thus the moisture content will be less in the cool air below which elevated thunderstorms reside. The MERH field (Fig. 11b) displays values of greater than $70 \%$ centered over the MCS location. The presence of high values of MERH likely increases the PE of the convective system by providing a moisture-rich environment, thereby reducing the entrainment of cooler, drier air. However, the spatial coverage of MERH displays an uncanny resemblance to the cloud shield of an MCC or an elliptical-shaped MCS. Even though we did not detect convectively contaminated soundings in our database, it is possible that the high MERH values may exhibit a slight positive bias because of ongoing convection (this topic will be addressed in more detail in section $4 d$ ).

\section{c. Vertical profiles of wind shear and instability}

Composite soundings were constructed at the centroid location and at an "inflow point" in the southerly lowlevel flow to provide further insight into the evolution of the thermodynamic and kinematic properties of the elevated MCS environment. The MCS centroid composite sounding was created by first generating 35 individual soundings for each centroid location listed in Table 2, at 50-hPa increments. The soundings were then averaged to create the composite sounding. The inflow composite sounding was created in a similar fashion based on points subjectively located within the southerly low-level inflow on the warm side of the surface boundary, upstream (about 250-300 km) of the elevated MCS centroids.

When compositing 35 individual soundings, considerable smoothing of detail is introduced: first by the initial Barnes analysis scheme and then by the averaging itself. This is most evident in parameters that are sensitive to small changes in the moisture or temperature distributions (such as CAPE) computed using data over 

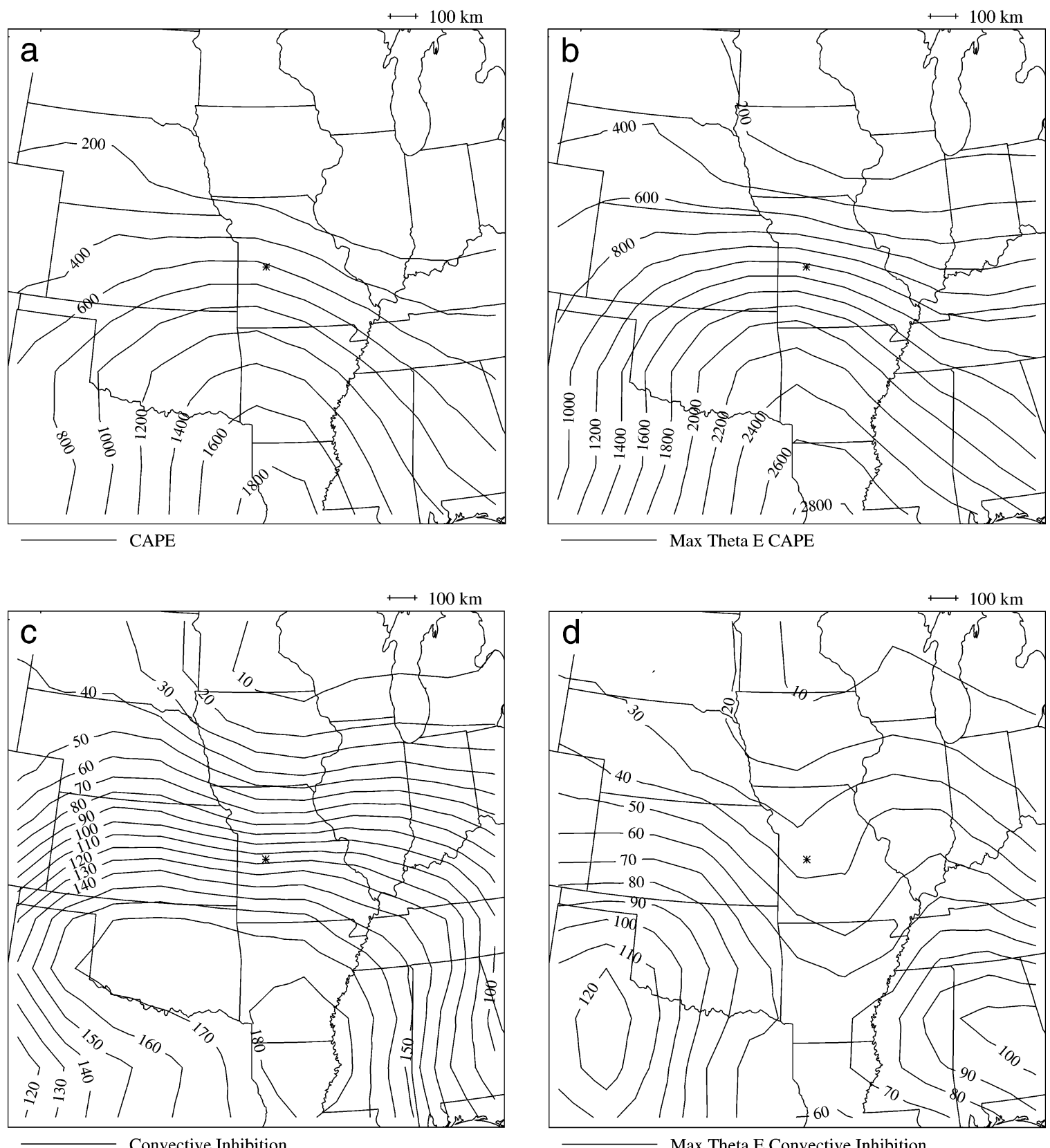

FIG. 10. Composite analysis of (a) CAPE ( $\mathrm{J} \mathrm{kg}^{-1}$ ) computed using the mean parcel from the lowest $100 \mathrm{hPa}$; (b) $\max -\theta_{e} \mathrm{CAPE}\left(\mathrm{J} \mathrm{kg}^{-1}\right)$, computed using the parcel with the maximum $\theta_{e}$ in the first $300 \mathrm{hPa}$ of the sounding; (c) CIN computed using the mean parcel from the lowest $100 \mathrm{hPa}$; and (d) CIN computed using the parcel with the maximum $\theta_{e}$ in the first $300 \mathrm{hPa}$ of the sounding.

the depth of the composite sounding or a substantial portion. Therefore, the following analysis focuses mostly on the low-level vertical wind shear and profiles of $\theta_{e}$ (based upon the averaged temperature and dewpoints) for both the MCS centroid and inflow sites.

At the MCS centroid location, the near-surface wind is from the east-southeast at about $2.5 \mathrm{~m} \mathrm{~s}^{-1}$ and veers to the southwest at about $10 \mathrm{~m} \mathrm{~s}^{-1}$ at $850 \mathrm{hPa}$. Above $850 \mathrm{hPa}$, the winds gradually increase in speed to $25 \mathrm{~m}$ $\mathrm{s}^{-1}$ at $300 \mathrm{hPa}$, with little directional change. In contrast, at the inflow site, the near-surface winds are from the south at $2 \mathrm{~m} \mathrm{~s}^{-1}$ and veer to the southwest at $15 \mathrm{~m} \mathrm{~s}^{-1}$ at $800 \mathrm{hPa}$. Above $800 \mathrm{hPa}$, the winds weaken slightly with little or no veering. Thus, the elevated MCS forms downstream from the LLJ situated over the inflow site.

More significant differences between the MCS centroid and the inflow site soundings show up in the profile of $\theta_{e}$. The centroid site (Fig. 12a) is characterized by a convectively stable boundary layer overlaid by a layer $(800-650 \mathrm{hPa})$ that is convectively unstable (i.e., a layer 

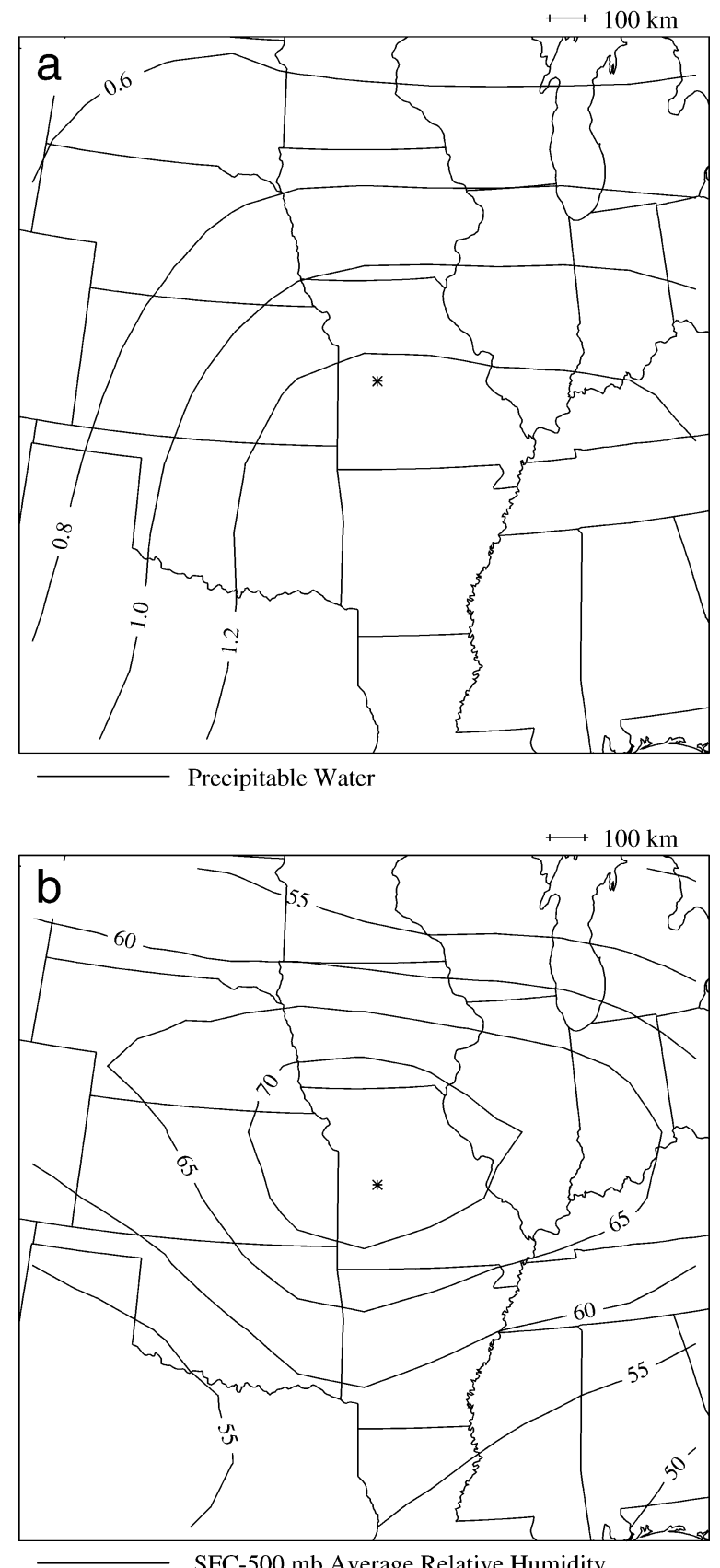

Fig. 11. Composite analysis of (a) precipitable water (in.) and (b) average relative humidity (surface-500 $\mathrm{hPa}$ ) (\%).

where $\theta_{e}$ decreases with height; $\partial \theta_{e} / \partial p>0$ or $\partial \theta_{e} / \partial z<$ $0)$. This stability stratification is consistent with the vertical wind profile noted above that promotes differential thermal/moisture advection. However, at the inflow site the profile of $\theta_{e}$ (Fig. 12b) reveals a shallow convectively stable layer with a deep layer $(950-600 \mathrm{hPa})$ of convectively unstable air aloft. The vertical shift in the location of maximum- $\theta_{e}$ air, from $950 \mathrm{hPa}$ at the inflow site to $800 \mathrm{hPa}$ at the centroid site, is consistent with
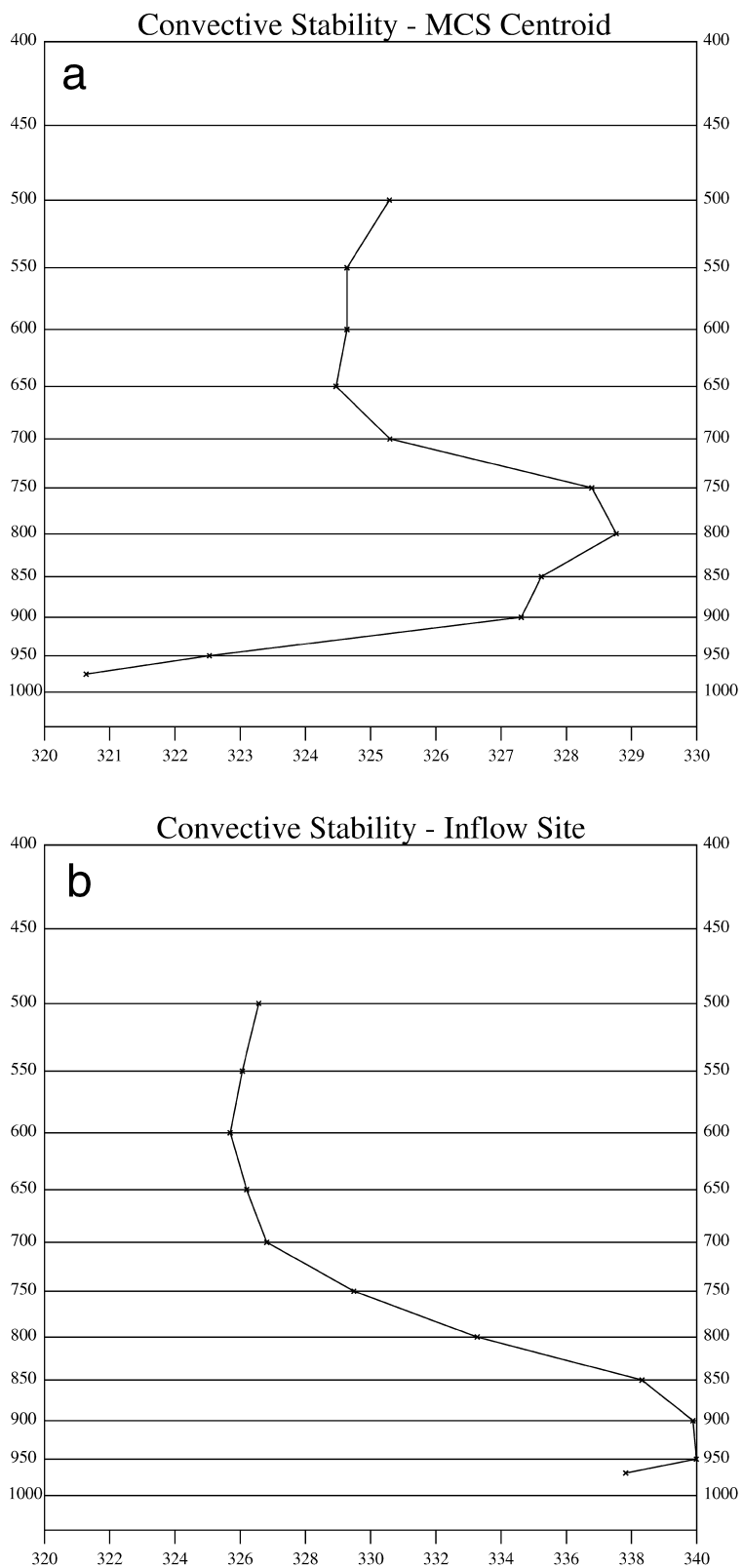

FIG. 12. Composite vertical profile of $\theta_{e}$ at the location of the (a) MCS centroid and (b) inflow point.

the northward transport of high- $\theta_{e}$ air above the frontal zone. The depth of the convectively unstable layer also changes from $350 \mathrm{hPa}$ at the inflow site to $150 \mathrm{hPa}$ at the MCS centroid.

\section{d. Representativeness of composite fields}

Several authors (Fritsch and Maddox 1981; Maddox 1983; Cotton et al. 1989; McAnelly and Cotton 1989) have noted that mature MCSs often modify their largescale environment. Because some mature MCSs were included in the current dataset, it is important to quantify 
their impact on the composite fields. Toward that end, the composite fields were recomputed using only those synoptic times that were either pre-MCS stage or less than $3 \mathrm{~h}$ after the MCS initiation, resulting in a total of 15 events being composited. The majority of the composited fields revealed little or no difference from the full dataset. The most notable differences resulted from those processes that exhibited diurnal trends, because the full dataset included more 1200 UTC event times. By including mainly 0000 UTC data times in the limited dataset, low-level wind fields were slightly weaker and more southerly, which is expected prior to the onset of the overnight inertial oscillation of the LLJ. In addition, the 0000 UTC data exhibited warmer low-level temperatures, thereby contributing to greater instability. Other differences, not associated with diurnal tendencies, include a lower MERH $(\sim 65 \%)$ and weaker upperlevel divergence $\left(\sim 1.5 \times 10^{-5} \mathrm{~s}^{-1}\right)$. These differences are likely due to the modification of the large-scale environment by the MCS, which includes stronger upperlevel divergence (Fritsch and Maddox 1981) and moistening of the atmospheric column (McAnelly and Cotton 1989). Last, it is significant to note that although the magnitudes were in some cases weaker than in the full dataset, spatial distributions of the fields were not substantially altered.

When discussing composite results, it is important to compare the individual cases with the composited fields to gauge the variability within the cases chosen for compositing. In this way we can ascertain whether the composite fields are representative of the typical conditions attending elevated convection or merely are displaying a statistical average that has no counterpart in nature.

To examine the robustness of the composite fields, the linear spatial correlation coefficient between the individual cases and the composite fields was computed. The linear spatial correlation coefficient (Snedecor and Cochran 1967) is defined as

$$
\mathrm{CORR}=\frac{\frac{1}{N} \sum_{i=1}^{N}\left(X_{i}-\bar{X}\right)\left(Y_{i}-\bar{Y}\right)}{S_{x} S_{y}},
$$

where $X_{i}\left(Y_{i}\right)$ represents the field of one of the parameters from one of the 35 analyses (composite field for one of the parameters), $\bar{X}(\bar{Y})$ is the mean of the individual (composite) parameter field, and $S_{x}\left(S_{y}\right)$ are the sample standard deviations of the two fields. High values of the correlation coefficient indicate that there is agreement between the pattern of the composite field and that for the individual analysis. Low or negative values of the spatial correlation coefficient can occur for a variety of reasons, including a shift in the orientation from the composite pattern, no discernable relationship to the composite pattern in the individual field, or even a reversal of the pattern from the composite field. As a consequence, occurrences of low spatial correlation coefficients need to be examined on a case-by-case basis.
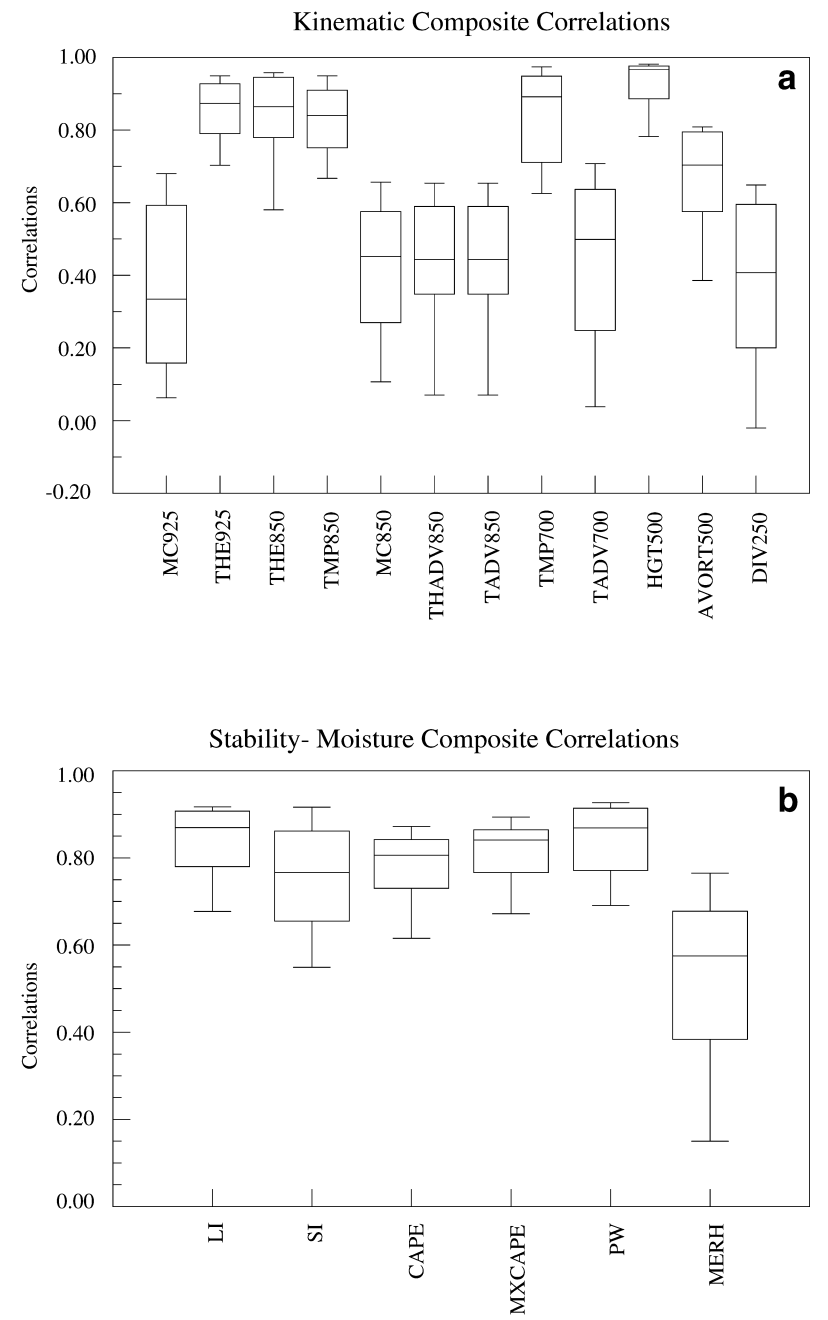

FIG. 13. Box-and-whisker plots displaying the range of correlations between the composite fields and the individual cases for (a) basic and derived kinematic fields and (b) stability and moisture fields. In each case the horizontal line within each box represents the 50th percentile, the top (bottom) line of the box is the 75th (25th) percentile, and the top (bottom) line outside the box represents the 90th (10th) percentile. (MC, moisture convergence; THE, $\theta_{e}$; TMP, temperature; THADV, $\theta_{e}$ advection; TADV, temperature advection; HGT, height; AVORT, absolute vorticity; DIV, divergence; LI, lifted index; SI, Showalter index; CAPE, CAPE computed using the mean parcel from the lowest $100 \mathrm{hPa}$; MXCAPE, max- $\theta_{e}$ CAPE; PW, precipitable water; MERH, surface-to-500-hPa mean relative humidity.)

As seen in Fig. 13a, basic parameters such as $\theta_{e}$ at 925 and $850 \mathrm{hPa}$, temperature at 850 and $700 \mathrm{hPa}$, and heights at $500 \mathrm{hPa}$ have relatively high correlation coefficients, with median values of $0.88,0.84,0.87,0.89$, and 0.97 , respectively. Derived parameters such as moisture convergence at 925 and $850 \mathrm{hPa}$, temperature advection at 850 and $700 \mathrm{hPa}, \theta_{e}$ advection at $850 \mathrm{hPa}$, absolute vorticity at $500 \mathrm{hPa}$, and divergence at $250 \mathrm{hPa}$ have lower correlation coefficients, with median values of $0.34,0.46,0.45,0.52,0.45,0.71$, and 0.41 , respectively. Thus, more variability is apparent in parameters that involve horizontal derivatives of basic variables. 
By taking horizontal derivatives, the noise in the basic variables is amplified, which likely contributes to the lower correlation values.

Inspection of those few cases associated with the poorest correlations revealed two basic scenarios. In the first scenario, the low correlation coefficient was due to a shift in the pattern. For example, the worst correlation value $(-0.24)$ was obtained for $250-\mathrm{hPa}$ divergence for event number $18 \mathrm{~b}$ (see Table 2 ). In this particular case, the area of maximum divergence was significantly offset to the northeast of the MCS centroid location. The divergence for the composite 250 -hPa field was negative in the corresponding region, resulting in a negative correlation. It appears that the divergence for this case was an integral part of the meso- $\alpha$-scale environment; however, it was displaced much farther northeast than in the composite field. In the second scenario, a low correlation resulted from a pattern that was discernibly different (i.e., not merely shifted) from the composite field. For example, in event number $8 b$ (see Table 2 ) the axis of moisture convergence at $925 \mathrm{hPa}$ was east of the MCS centroid location and oriented in a north-south direction. This results in a near-zero correlation $(-0.01)$ because the composite $925-\mathrm{hPa}$ moisture convergence axis (see Fig. 5c) extends to the west-southwest of the MCS centroid location.

Correlations related to stability and moisture (Fig. 13b) generally fell between the basic and derived field correlations seen in Fig. 13a. The median correlation coefficients for stability-related parameters such as LI, SI, mean parcel CAPE, max- $\theta_{e}$ CAPE, PW, and MERH were $0.87,0.77,0.81,0.84,0.87$, and 0.58 , respectively. It is likely that the SI correlations are lower because they are derived using data from specific levels that may not be appropriate for identifying the characteristics of the air mass that overlies the frontal zone (e.g., $850 \mathrm{hPa}$ may be below the frontal zone in some cases). In contrast, the mean parcel CAPE and LI use an average parcel within the boundary layer, and $\max -\theta_{e} \mathrm{CAPE}$ explicitly uses the highest $\theta_{e}$ value in the lowest 300 $\mathrm{hPa}$ of the sounding to identify the stability characteristics of the air mass. The poorest correlation value in Fig. 13b was for the MERH. Inspection of several events with the lowest correlation revealed that the decrease of MERH away from the MCS centroid (see Fig. 11b) was not consistently seen in the individual events.

Note that even when an individual field from a case did not correlate well with the composite pattern, other fields from that case were not necessarily poorly correlated. In about $50 \%$ of the cases, at least 10 parameters, out of 18 , had correlations coefficients that exceeded the median correlation value for that parameter. This result provides evidence that the composite patterns presented herein are reliable signatures of the typical environmental conditions that accompany elevated convection attended by heavy rainfall.

\section{Summary and conclusions}

The environmental conditions of warm-season heavy convective rainfall in the central United States associated with elevated thunderstorms have been studied using storm-relative composites. Analysis of the data offers valuable insight into the large-scale patterns and the physical processes responsible for these events. In general, the overall synoptic pattern is similar to the "frontal" archetype flash-flood pattern described by Maddox et al. (1979). However, since the composites were based upon a limited dataset and geographical domain, the applicability of these results to other regions has not been established.

Based upon the composite results, a cross-sectional schematic of the MCS environment was constructed (Fig. 14), and it revealed that elevated MCSs are centered, on average, $160 \mathrm{~km}$ north of an east-west-oriented surface front within the cool sector. The exact position of the MCS with respect to the surface frontal boundary will vary by case because it is a function of the slope of the isentropic surfaces (i.e., thermal gradient), magnitude and orientation of the low-level inflow, and moisture content and degree of saturation of the incoming air. A south-southwesterly LLJ transports high- $\theta_{e}$ air northward along and above the cool, stable layer marking the sloped low-level frontal zone. Southwesterly midtropospheric flow advects lower- $\theta_{e}$ air over the warm, moist high- $\theta_{e}$ air, resulting in a layer of elevated convective instability. Large-scale isentropic ascent, suggested by the lower-tropospheric warm-air advection and frontogenesis in the presence of the entrance region of the ULJ, appears to be instrumental in lifting the layer to saturation. Moisture convergence within the left-exit region of the LLJ helps to initiate deep convection in the unstable layer along or above the frontal zone as parcels are lifted to their LFC. The LLJ contributes to an axis of moisture convergence aligned nearly parallel to the surface boundary and cloud-layer winds, which promotes cell training and subsequent high rainfall totals (Junker et al. 1999).

Plan-view schematics that summarize some of the key composite features and parameters found in this study are displayed in Fig. 15. The low-level features (Fig. 15a) highlighted include the presence of a west-east quasi-stationary front, a moderate north-south $\theta_{e}$ gradient with the MCS centroid embedded on the cool side of the front, and a south-southwesterly LLJ directed nearly normal to the boundary. Two other important low-level features include a southwest-northeast, elongated moisture convergence axis at $925 \mathrm{hPa}$ found along and on the cool side of the boundary upstream from the MCS centroid and a maximum of positive $850-\mathrm{hPa} \theta_{e}$ advection nearly centered over the MCS centroid. Middle-upper-tropospheric features (Fig. 15b) pertinent to the elevated MCS environment include broad southwesterly midtropospheric flow, with the MCS centroid located over the inflection point, and moderately high 


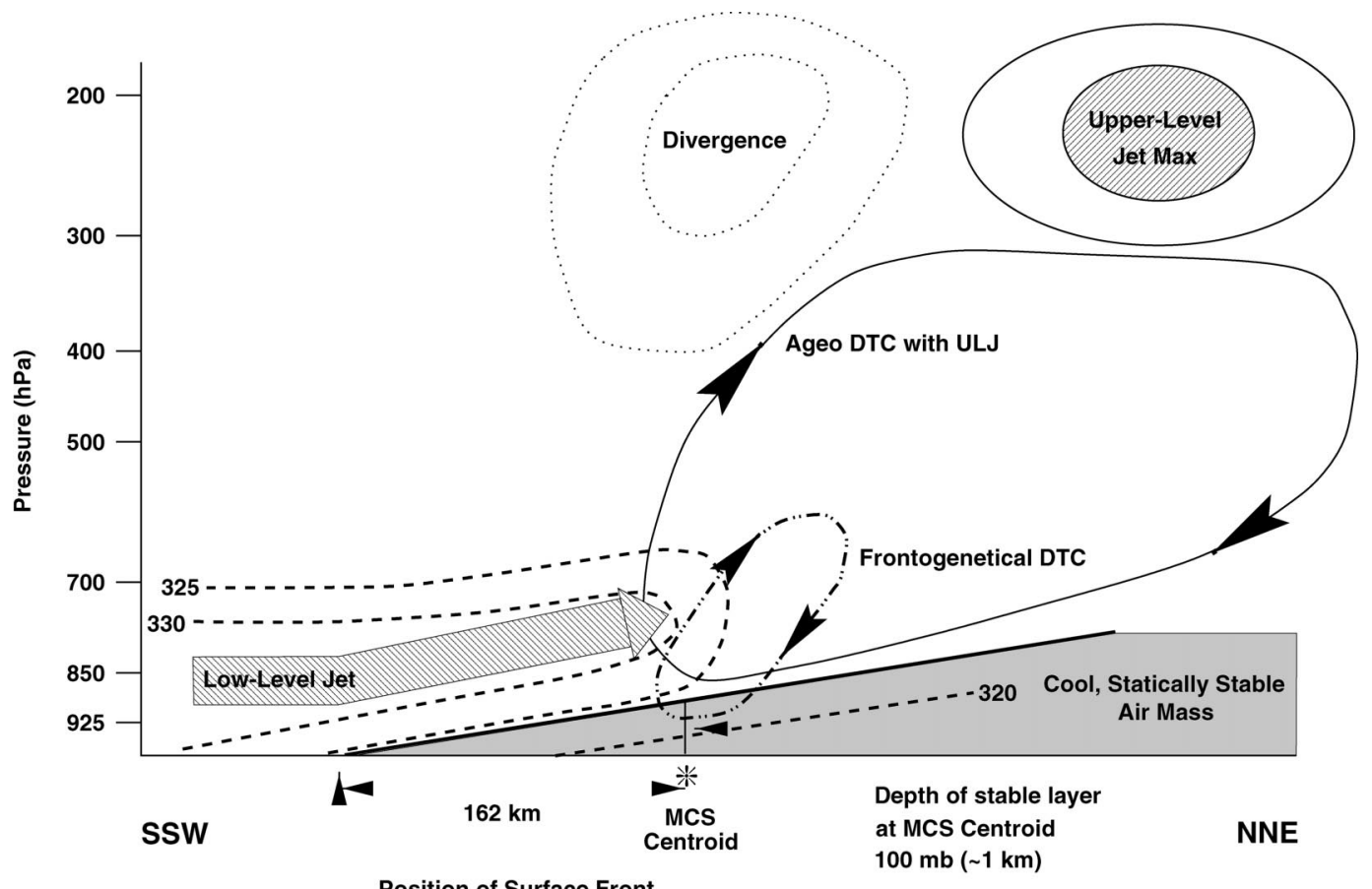

FIG. 14. Schematic cross-sectional view taken parallel to the LLJ across the frontal zone. Dashed lines represent typical $\theta_{e}$ values, the large stippled arrow represents the ascending LLJ, the thin dotted oval represents the ageostrophic direct thermal circulation associated with the upper-level jet streak, and the thick dashed oval represents the direct thermal circulation associated with the low-level frontogenetical forcing. The area aloft enclosed by dotted lines indicates upper-level divergence; the area aloft enclosed by solid lines denotes location of upper-level jet streak. Note that in this cross section the horizontal distance between the MCS and the location of the upper-level jet maximum is not to scale.

mean surface-to-500-hPa relative humidity. The MCS centroid is also typically located in the right-entrance region of the ULJ, which is a favored region of upperlevel divergence.

Composite analyses also reveal that the location of the elevated MCS centroid is favored just east of the maximum $\theta_{e}$, within a region of warm-air advection and moisture convergence at $850 \mathrm{hPa}$. Analysis of max- $\theta_{e}$ CAPE reveals values that are almost 2 times those of the mean parcel CAPE over the MCS centroid location. Moreover, large values of max- $\theta_{e}$ and mean parcel CIN are found south of the frontal boundary and suppress the development of convection. However, in the vicinity of the MCS centroid, values of max- $\theta_{e}$ CIN are onethird of the mean parcel CIN. As a consequence, air parcels subjected to sloped ascent above the frontal boundary will more easily overcome negative buoyancy to produce convection.

Relatively high correlation coefficients of the individual fields confirm that operational forecasters can apply the patterns/signals displayed in the composites with prognostic numerical model data to help to diagnose regions favorable for organized elevated thunderstorms that produce heavy rainfall. Although quantifying the significant parameters used to diagnose a favorable region of elevated convection leading to heavy rain is important, it is equally as important to note the spatial distribution of these variables. In this way a conceptual model can be constructed that depicts how critical physical processes synergistically interact to create a mesoscale environment favorable for the development of elevated thunderstorms.

Acknowledgments. The authors thank Heather Summer, Kathleen O'Connor, Scott Watson, and Sam Ng for their assistance during portions of this study. Thanks are also extended to Mr. Steven Thomas (MIC) and Mr. Ron Przybylinski (SOO) of WFO St. Louis for administrative support. The authors thank the three reviewers for their constructive comments in improving the original manuscript. Primary funding for this research is from the Collaborative Science, Technology, and Applied Research (CSTAR) Program of NOAA under Award NA07WA0065. Preliminary research for this effort was funded from a subaward (UCAR S97-86991) under a cooperative agreement between NOAA and the University Corporation for Atmospheric Research (UCAR). The views expressed herein are those of the authors and do not necessarily reflect the views of NOAA, its subagencies, or UCAR. 

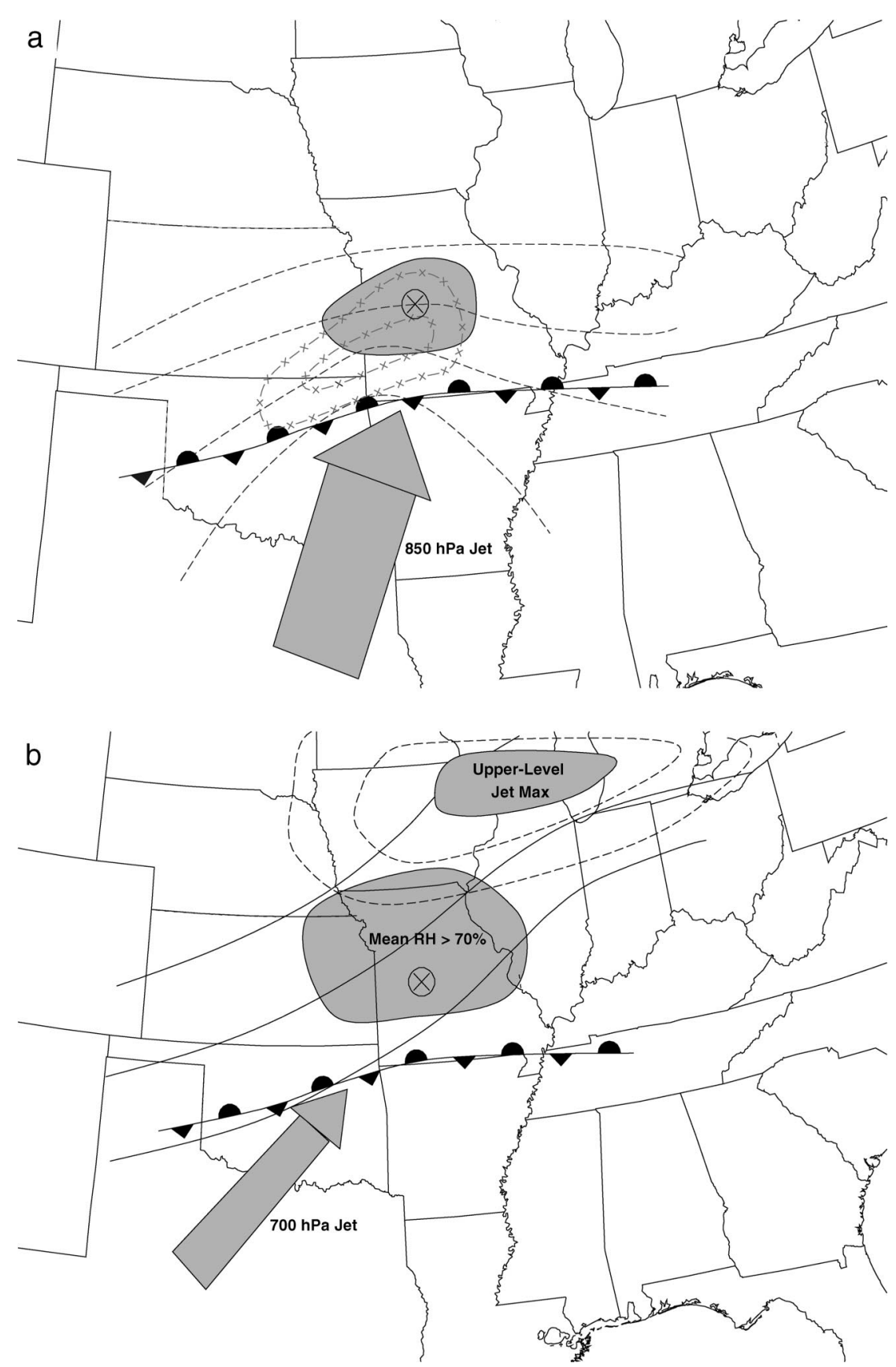

FIG. 15. Schematic diagrams that summarize the typical conditions associated with warmseason elevated thunderstorms attended by heavy rainfall: (a) low-level plan view and (b) middleupper-level plan view. In (a), dashed lines are representative $\theta_{e}$ values decreasing to the north, dashed-cross lines represent $925-850-\mathrm{hPa}$ moisture convergence maxima, the shaded area is a region of maximum $\theta_{e}$ advection, the broad stippled arrow denotes the LLJ, the encircled X represents the MCS centroid location, and the front is indicated using standard notation. In (b), dashed lines are isotachs associated with the upper-level jet, solid lines are representative height lines at $500 \mathrm{hPa}$, the stippled arrow denotes the $700-\mathrm{hPa}$ jet, and the shaded area indicates where the mean surface-to-500-hPa relative humidity exceeds $70 \%$. 


\section{REFERENCES}

Anderson, C. J., and R. W. Arritt, 1998: Mesoscale convective complexes and persistent elongated convective systems over the United States during 1992 and 1993. Mon. Wea. Rev., 126, 578599.

—, W. A. Gallus Jr., R. W. Arritt, and J. S. Kain, 2002: Impact of adjustments in the Kain-Fritsch convective scheme on QPF of elevated convection. Preprints, 19th Conf. on Weather Analysis and Forecasting, San Antonio, TX, Amer. Meteor. Soc., 23-24.

Augustine, J. A., and F. Caracena, 1994: Lower-tropospheric precursors to nocturnal MCS development over the central United States. Wea. Forecasting, 9, 116-135.

Barnes, S. L., 1973: Mesoscale objective map analysis using weighted time series observations. NOAA Tech. Memo. ERL NSSL 62, 60 pp. [NTIS COM-73-10781.]

Bonner, W. D., 1968: Climatology of the low-level jet. Mon. Wea. Rev., 96, 833-850.

Borneman, R., and C. Kadin, 1994: Catalogue of heavy rainfall cases of six inches or more over the continental U.S. during 1993. NOAA Tech. Rep. NESDIS 80, 154 pp.

Colman, B. R., 1990a: Thunderstorms above frontal surfaces in environments without positive CAPE. Part I: A climatology. Mon. Wea. Rev., 118, 1103-1121.

_ 1990b: Thunderstorms above frontal surfaces in environments without positive CAPE. Part II: Organization and instability mechanisms. Mon. Wea. Rev., 118, 1123-1144.

Cotton, W. R., M. S. Lin, R. L. McAnelly, and C. J. Tremback, 1989: A composite model of mesoscale convective complexes. Mon. Wea. Rev., 117, 765-783.

Doswell, C. A., and E. K. Rasmussen, 1994: The effect of neglecting the virtual temperature correction on CAPE calculations. Wea. Forecasting, 9, 625-629.

—_ H. E. Brooks, and R. A. Maddox, 1996: Flash flood forecasting: An ingredients-based methodology. Wea. Forecasting, 11, 560581.

Fritsch, J. M., and R. A. Maddox, 1981: Convectively driven mesoscale weather systems aloft. Part I: Observations. J. Appl. Meteor., 20, 9-19.

— R. J. Kane, and C. R. Chelius, 1986: The contribution of mesoscale convective weather systems to the warm season precipitation in the United States. J. Appl. Meteor., 25, 1333-1345.

Glass, F. H., D. L. Ferry, J. T. Moore, and S. M. Nolan, 1995: Characteristics of heavy convective rainfall events across the midMississippi valley during the warm season: Meteorological conditions and a conceptual model. Preprints, 14th Conf. on Weather Forecasting and Analysis, Dallas, TX, Amer. Meteor. Soc., 3441.

Grant, B. N., 1995: Elevated cold-sector severe thunderstorms: A preliminary study. Natl. Wea. Dig., 19 (4), 25-31.

Jankov, I., and W. A. Gallus Jr., 2002: Contrast between good and bad forecasts of warm season MCSs in $10 \mathrm{~km}$ Eta simulations using two convective schemes. Preprints, 19th Conf. on Weather Analysis and Forecasting, San Antonio, TX, Amer. Meteor. Soc., 242-243.

Junker, N. W., R. S. Schneider, and R. A. Scofield, 1995: The meteorological conditions associated with the great Midwest flood of 1993. Preprints, 14th Conf. on Weather Analysis and Forecasting, Dallas, TX, Amer. Meteor. Soc., (J4)13-(J4)17.

— — - and S. L. Fauver, 1999: A study of heavy rainfall events during the great Midwest flood of 1993. Wea. Forecasting, 14, 701-712.

Juying, X., and R. A. Scofield, 1989: Satellite-derived rainfall estimates and propagation characteristics associated with mesoscale convective systems (MCSs). NOAA Tech. Memo. NESDIS 25, $49 \mathrm{pp}$.

Koch, S. E., M. DesJardins, and P. J. Kocin, 1983: An interactive Barnes objective map analysis scheme to use with satellite and conventional data. J. Climate Appl. Meteor., 22, 1487-1503.

Maddox, R. A., 1980: Mesoscale convective complexes. Bull. Amer. Meteor. Soc., 61, 1374-1387.

__ 1983: Large-scale meteorological conditions associated with midlatitude, mesoscale convective complexes. Mon. Wea. Rev. 111, 1475-1493.

- and C. A. Doswell, 1982: An examination of jet stream configurations, $500 \mathrm{hPa}$ vorticity advection, and low-level thermal advection patterns during extended periods of intense convection. Mon. Wea. Rev., 110, 184-197.

— C. F. Chappell, and L. R. Hoxit, 1979: Synoptic and meso- $\alpha$ scale aspects of flash flood events. Bull. Amer. Meteor. Soc., 60, $115-123$.

McAnelly, R. L., and W. R. Cotton, 1989: The precipitation life cycle of mesoscale convective complexes over the central United States. Mon. Wea. Rev., 117, 784-808.

McNulty, R. P., 1978: On upper tropospheric kinematics and severe weather occurrence. Mon. Wea. Rev., 106, 662-672.

Merritt, J. H., and J. M. Fritsch, 1984: On the movement of heavy precipitation areas in mid-latitude mesoscale convective complexes. Preprints, 10th Conf. on Weather Analysis and Forecasting, Clearwater Beach, FL, Amer. Meteor. Soc., 529-536.

Moore, J. T., and G. E. VanKnowe, 1992: The effect of jet-streak curvature on kinematic fields. Mon. Wea. Rev., 120, 2429-2441.

— A. A. Czarnetzki, and P. S. Market, 1998: Heavy precipitation associated with elevated thunderstorms formed aloft in a convectively unstable layer. Meteor. Appl., 5, 373-384.

NOAA, 1994: The Great Flood of 1993. Natural Disaster Survey Rep., NOAA, Rockville, MD, 317 pp.

Petterssen, S., 1956: Weather Analysis and Forecasting. Vol. 1. McGraw-Hill, 428 pp.

Rochette, S. M., and J. T. Moore, 1996: Initiation of an elevated mesoscale convective system associated with heavy rainfall. Wea. Forecasting, 11, 443-457.

—_ —, and P. S. Market, 1999: The importance of parcel choice in elevated CAPE computations. Natl. Wea. Dig., 23 (4), 20 32

Shi, J., and R. A. Scofield, 1987: Satellite observed mesoscale convective system (MCS) propagation characteristics and a 3-12 hour heavy precipitation forecast index. NOAA Tech. Memo. NESDIS 20, 43 pp.

Snedecor, G. W., and W. G. Cochran, 1967: Statistical Methods. 6th ed. The Iowa State University Press, 593 pp.

Williams, E., and N. Renno, 1993: An analysis of the conditional instability of the tropical atmosphere. Mon. Wea. Rev., 121, 2136 